\title{
Processes of interannual mixed layer temperature variability in the thermocline ridge of the Indian Ocean
}

\author{
B. Praveen Kumar ${ }^{1,}{ }^{*}$, J. Vialard ${ }^{2}$, M. Lengaigne ${ }^{2}$, V. S. N. Murty ${ }^{3}$, G. R. Foltz ${ }^{4}$, M. J. McPhaden ${ }^{5}$, \\ S. Pous ${ }^{2,6}$, C. de Boyer Montégut ${ }^{7}$
}

\footnotetext{
${ }^{1}$ Indian National Centre for Ocean Information Services, Ministry of Earth Sciences, Govt. of India, Hyderabad, India

${ }^{2}$ Laboratoire d'Océanographie Expérimentation et Approches Numériques, CNRS, UPMC, IRD, MNHN, Paris, France

${ }^{3}$ CSIR-National Institute of Oceanography, Regional Centre, Vishakhapatnam, India

${ }_{5}^{4}$ Atlantic Oceanographic and Meteorological Laboratory, NOAA, Miami, FL, USA

${ }^{5}$ Pacific Marine Environmental Laboratory, NOAA, Seattle, WA, USA

${ }^{6}$ LMI ICEMASA, IRD, Department of Oceanography, University of Cape Town, Cape Town, South Africa

7 IFREMER, Centre de Brest, Laboratoire d'Océanographie Spatiale, Pointe du Diable, B.P. 70, 29280, Plouzane, France
}

*: Corresponding author : B. Praveen Kumar, email address : praveen.b@incois.gov.in

\begin{abstract}
:
Sea-surface temperature interannual anomalies (SSTAs) in the thermocline ridge of the southwestern tropical Indian Ocean (TRIO) have several well-documented climate impacts. In this paper, we explore the physical processes responsible for SSTA evolution in the TRIO region using a combination of observational estimates and model-derived surface layer heat budget analyses. Vertical oceanic processes contribute most to SSTA variance from December to June, while lateral advection dominates from July to November. Atmospheric fluxes generally damp SSTA generation in the TRIO region. As a result of the phase opposition between the seasonal cycle of vertical processes and lateral advection, there is no obvious peak in SSTA amplitude in boreal winter, as previously noted for heat content anomalies. Positive Indian Ocean Dipole (IOD) events and the remote influence of EI Niño induce comparable warming over the TRIO region, though IOD signals peak earlier (NovemberDecember) than those associated with El Niño (around March-May). Mechanisms controlling the SSTA growth in the TRIO region induced by these two climate modes differ strongly. While SSTA growth for the IOD mostly results from southward advection of warmer water, increased surface shortwave flux dominates the EI Niño SSTA growth. In both cases, vertical oceanic processes do not contribute strongly to the initial SSTA growth, but rather maintain the SSTA by opposing the effect of atmospheric negative feedbacks during the decaying phase.
\end{abstract}

Keywords: Thermocline ridge of the Indian Ocean ; Surface temperature interannual variability ; ENSO ; IOD 
The southwestern tropical Indian Ocean is characterized by a climatologically shallow thermocline in the $5^{\circ} \mathrm{S}-12^{\circ} \mathrm{S}$ latitudinal band (Figure 1), known as the Seychelles-Chagos Thermocline Ridge (SCTR - Hermes and Reason. 2008; Vialard et al. 2009), Seychelles Dome (Yokoi et al. 2008) or Thermocline Ridge of the Indian Ocean (TRIO - Jayakumar et al. 2011). The TRIO is primarily maintained by wind stress curl between the southeasterly trades in the south and equatorial westerlies to the north (Xie et al. 2002, McCreary et al. 1993, Vialard et al. 2009). The shallow thermocline favours a strong connection between subsurface variations and the surface, allowing ocean dynamics to affect Sea Surface Temperature (SST) in this region (Xie et al. 2002). SST in austral summer (Figure 1) is also above the $\sim 28.5^{\circ} \mathrm{C}$ threshold for deep atmospheric convection (Graham and Barnett, 1987) in the TRIO so that small SST variations can induce large atmospheric responses.

The combination of coupling between the subsurface and SST, and the sensitivity of the atmosphere to the underlying SST, contributes to strong air-sea interactions on intraseasonal to interannual time scales (e.g. Vialard et al. 2009 and references therein) in the TRIO region, which affects remote areas through atmospheric teleconnections. For example, anomalously high heat content in the ridge region is associated with increased cyclonic activity near Madagascar and La Réunion (Jury et al. 1999; Xie et al. 2002). Anomalously warm SST in the TRIO region also induces above-average rainfall along the Western Ghats of India during the following monsoon (Vecchi and Harrison 2004; Izumo et al. 2008). Atmospheric model experiments suggest that these SST anomalies force a substantial fraction of interannual precipitation anomalies over the western Pacific and maritime continent (Annamalai et al. 2005) and influence the northern hemisphere extratropical circulation during boreal winter (Annamalai et al. 2007). These climatic consequences provide a strong incentive to better understand the mechanisms driving the SST variations in the TRIO region.

At intraseasonal timescales, the Madden Julian Oscillation (MJO) is the strongest mode of atmospheric variability in the tropics, with clear impacts on tropical rainfall (Madden and Julian. 1974; Zhang 2005) and teleconnections to mid-latitude weather (Cassou, 2008). The MJO initially develops in the western Tropical Indian Ocean before propagating eastward at $\sim 5 \mathrm{~ms}^{-1}$ through the northwestern Australian basin (Vialard et al. 2013). The TRIO region has one of the strongest SST responses to the MJO in the global tropics and hence potentially a strong feedback onto the MJO (e.g. Duvel 2012). The strong MJOinduced SST signals in the TRIO region motivated many studies on the processes driving SST variations in this region (e.g. Harrison and Vecchi 2001, Saji et al. 2006, Duvel and Vialard 2007, Vialard et al. 2008). Recent studies (Jayakumar et al. 2011) suggest that heat fluxes at the air-sea interface generally dominate MJO-induced SST variations in the TRIO region, though vertical oceanic processes (entrainment, mixing and upwelling) can occasionally be as large.

Several recent studies investigated the processes controlling the seasonal cycle in the TRIO region. Hermes and Reason (2008) and Yokoi et al. (2009) focused on the mechanisms that drive the seasonal cycle of thermocline depth and found strong influences from local wind forcing and wave propagation. Foltz et al. (2010), Halkides and Lee (2011) and Yokoi et al. (2012) focused on the mechanisms responsible for the SST annual cycle. Foltz et al. (2010) and Yokoi et al. (2012) found that air-sea fluxes drive seasonal SST changes most of the year, except during austral winter, when meridional advection contributes substantially due to the presence of a strong meridional SST gradient. They found that cooling from oceanic vertical processes balance the warming effects of surface fluxes and advection throughout the year, but with weaker seasonal variations compared to 
surface fluxes and advection. Halkides and Lee (2011) found a comparatively larger effect of vertical processes and smaller effect of lateral advection on the seasonal cycle of SST.

There is also pronounced SST variability in the TRIO region on interannual timescales. This interannual variability has two main origins. First, the Indian Ocean Dipole is an intrinsic mode of variability of the Indian Ocean, arising from positive air-sea interactions (e.g. Saji et al. 1999, Webster et al. 1999, Murtugudde et al. 2000). Positive IOD events are associated with negative SST anomalies close to the coast of Sumatra and warm anomalies in the western part of the basin, including the TRIO region. Second, the EI NiñoSouthern Oscillation (ENSO) in the tropical Pacific exerts strong external forcing on the Indian Ocean. ENSO forcing can, in some instances trigger IOD events (Annamalai et al. 2003, Meyers et al. 2007; McPhaden and Nagura, 2013). However, the most systematic remote effect of ENSO in the Indian Ocean is a basin scale warming during and after ENSO's peak (Klein et al., 1999; Lau and Nath, 2000), in particular in the TRIO region (Xie et al. 2009). Wind anomalies associated with both positive IOD and EI Niño events result in downward Ekman pumping in the eastern Indian Ocean (Yu et al. 2005, Rao and Behera 2005). This deepens the thermocline south of the equator, forcing oceanic downwelling Rossby waves that propagate to the TRIO region (Masumoto and Meyers 1998, Xie et al. 2002, Tozuka et al. 2010, McPhaden and Nagura, 2013). Heat content perturbations associated with EI Niño Southern Oscillation (ENSO) appear to dominate south of $10^{\circ} \mathrm{S}$, while those associated with the IOD appear to be strongest northward (Yu et al. 2005, Currie et al. 2013). However, because the IOD events tend to co-occur with EI Niño events, it is difficult to cleanly isolate their impacts on the TRIO region.

Despite the strong climate impacts of interannual SST anomalies (hereafter, SSTA) in the TRIO region, there have been few studies analysing the processes responsible for those anomalies. Tozuka et al. (2010) discussed the interannual variability of the $20^{\circ} \mathrm{C}$ isotherm depth (and hence of the heat content) in this region. They found that interannual variability of this heat content is phase locked to the seasonal cycle and strongest in austral summer (also see Figure 2b). They also showed that interannual heat content variations are not only remotely forced through planetary waves, but also forced locally by Ekman pumping. The local Ekman pumping mechanism was corroborated in a recent modelling study by Trenary and Han (2012). Xie et al. (2002) showed that thermocline depth anomalies are correlated at $\sim 0.6$ with SSTA in the TRIO region and interpreted the high correlation as a sign that the subsurface and surface are connected through vertical oceanic processes. They suggested that the associated thermocline deepening in the TRIO region contributes significantly to the SST warming, probably through reduced cooling via vertical oceanic processes. Xie et al. (2009) suggested that this mechanism helps to maintain anomalously warm Indian Ocean SST after EI Niño ends and to prolong the impact of Indian Ocean SST anomalies on regional climate (the so-called Indian Ocean capacitor" effect). Murtugudde et al. (2000) and Du et al. (2009) did not focus on the TRIO region, but showed that a combination of vertical oceanic processes and meridional advection contributed to the warming in this region in the aftermath of the 1997 IOD and EI Niño. Santoso et al. (2010) did not focus on the TRIO region either, but their heat budget analyses suggest an important role for vertical oceanic processes in driving SSTA in the region. Yokoi et al. (2012) provides the most detailed analysis of SSTA in the TRIO region. They confirmed Xie et al.'s (2002) finding that the SST is warmer when the thermocline is anomalously deep because of vertical oceanic processes, but also identified a contribution from meridional advection to the warming and a negative feedback from air-sea fluxes.

There have been only a handful of studies on the processes controlling interannual SST variations in the TRIO region, and their results are not always consistent. In this paper we address this knowledge gap, focusing on two specific issues. First, unlike thermocline depth anomalies that are clearly largest in austral winter (Tozuka et al. 2010, Figure 2b), there is no clear seasonal phase locking of SSTA, and its amplitude does not vary as much throughout the year (the maximum of the SSTA seasonal cycle is only 1.5 times larger than 
the minimum, compared to 2.5 times for D20, Figure 2c). Our first objective is therefore to explain the modest seasonality in the amplitude of interannual TRIO SSTA. Second, previous studies have examined the processes controlling SSTA in the TRIO region without unambiguously linking them to either ENSO or the IOD. Our second objective will therefore be to clarify the relationships between SST anomalies in the TRIO region and these two modes of climate variability.

The rest of the paper is constructed as follows. Section 2 presents the various datasets and the model simulations that we use in this paper, and our methodology for analysing them. In section 3, we briefly discuss how the seasonal SST budget in the TRIO region compares with previous studies, and then evaluate the model using long time-series and insitu data collected during the Cirene cruise in early 2007 (Vialard et al. 2009). Processes driving SSTA in the TRIO region are discussed in section 4, focusing on the seasonality of SSTA amplitude. In section 5, we isolate the impacts of the IOD and ENSO on SSTA and the processes associated with those impacts. This is followed by a summary and discussion in section 6 .

\section{Methods and Data Sets}

\subsection{Modelling approach}

The analyses in this paper are based on two configurations of the NEMO ocean general circulation model (Madec 2008). Both versions use the same model physics and forcing strategy; the only differences are the model domain, resolution and experiment length.

The first model configuration is an Indian Ocean sub-domain $\left(27^{\circ} \mathrm{E}\right.$ to $142^{\circ} \mathrm{E}, 33^{\circ} \mathrm{S}$ to $\left.30^{\circ} \mathrm{N}\right)$ of the global $1 / 4^{\circ}$ resolution configuration described by Barnier et al. (2006). Open boundary conditions are applied along the oceanic portions of the domain boundaries, with velocity, temperature and salinity from an interannual global $1 / 4^{\circ}$ simulation (Treguier et al. 2001) that has been extensively validated over the tropical Indo-Pacific region (Lengaigne et al. 2012; Keerthi et al. 2012; Nidheesh et al. 2012; Vialard et al. 2013). The model starts at rest from the World Ocean Atlas Temperature and Salinity climatologies (Locarnini et al. 2010) and is forced from 1990 to 2007 with the Drakkar Forcing Set 4 (DFS4) described in Brodeau et al. (2010). DFS4 turbulent fluxes are from the CORE dataset (Large and Yeager. 2004), which is derived from the basic variables in ERA 40 (Uppala et al. 2005; until 2002) and ERA-Interim reanalyses (Dee et al. 2011; after 2002). Radiative fluxes are based on corrected ISCCP-FD surface radiation (Zhang et al. 2004), while precipitation data are based on a blending of several satellite products, including two of the most widely used datasets: GPCP (Huffman et al. 1997) and CMAP (Xie and Arkin 1997). All atmospheric fields are corrected to avoid temporal discontinuities and remove known biases (see Brodeau et al. 2010 for details). This experiment successfully reproduces observed intraseasonal SST variations in austral winter in the TRIO region (Jayakumar et al. 2011).

We use the simulation above in most of the following analyses, focusing on the 1993-2007 period. One of our aims is to differentiate the IOD and ENSO SST signatures in the TRIO region, for which a longer simulation period is necessary. We hence analyse the output from a lower resolution global run $\left(2^{\circ}\right.$ grid everywhere, refined to $0.5^{\circ}$ meridionally within $5^{\circ}$ of the equator) with the configuration described above. The model is run for the 1960-2007 period, starting at rest from the World Ocean Atlas Temperature and Salinity climatologies and using the DFS4 forcing.

Apart from their model domain and forcing periods, the two simulations share many similarities and produce a similar solution over the TRIO region for their common period 
(with the $14^{\circ}$ version performing slightly better for the comparisons in figures 4 to 7 , not shown). There is no SST relaxation in any of the two experiments and the surface salinity is relaxed to the World Ocean Atlas monthly surface salinity climatology (Locarnini et al. 2010), with a relaxation timescale of 6 months for a 30m-thick layer. All of the results below are based on the $1993-2007$ outputs of the $1 / 4^{\circ}$ simulation, unless otherwise specified.

\subsection{Datasets}

In this paper we will use observational datasets for two purposes. First, we evaluate our ocean model and its consistency with observations. Second, we compute alternative upper ocean heat budgets from observations, in addition to those from the model. The observational data sets, described below, include gridded SST and heat fluxes, ocean surface currents and mixed layer depth. To complement the gridded data, we also use measurements from the Cirene cruise (Vialard et al. 2009), which provided in-situ samples within the TRIO region in early 2007 , immediately following one of the strongest IOD events in recent history.

Gridded SST, heat fluxes and wind stress data were obtained from the recently released TropFlux product (Praveen Kumar et al. 2012, 2013). TropFlux provides these fields on $1^{\circ} \times 1^{\circ}$, daily grids over the global tropical oceans $\left(30^{\circ} \mathrm{S}-30^{\circ} \mathrm{N}\right)$ from 1979 to $3-4$ months behind present (http://www.locean-ipsl.upmc.fr/tropflux/). TropFlux uses in situ data from the Tropical Moored Buoy Array (McPhaden et al, 2010) to correct ERA-interim (Dee et al. 2011) surface meteorological data and ISCCP (Zhang et al. 2004) surface shortwave fluxes for biases in their means and amplitudes. Surface heat and momentum fluxes are then computed using the COARE v3.0 algorithm (Fairall et al. 2003). TropFlux is one of the best performers in terms of interannual variability compared to other available datasets (see Praveen Kumar et al. 2012).

The Ocean Surface Current Analysis - Realtime (OSCAR; http://www.oscar.noaa.gov/) project provides near real time, 5-day resolution gridded estimates of currents averaged in the upper $30 \mathrm{~m}$ since 1992 October (Bonjean and Lagerloef. 2002). The OSCAR formulation combines geostrophic currents from satellite-derived sea level, as well as the wind-driven (Ekman) contribution. We will also use AVISO altimeter measurements of sea surface height (SSH) produced by the CLS Space Oceanography Division. This dataset combines the joint US-French missions TOPEX/POSEIDON (October 1992 to October 2002) and JASON-1 or Envisat (October 2002 to present) and is available at weekly intervals.

The mixed layer depth (MLD) data used in this study is based on individual in situ profiles, including those in the world ocean database and profiles obtained from Argo autonomous profilers (de Boyer et al. 2004; http://www.locean-ipsl.upmc.fr/ cdblod/mld.html). We use a global seasonal climatology (de Boyer et al. 2004) and an interannual dataset for the Indian Ocean (Keerthi et al. 2013). MLD is calculated using a $0.2^{\circ} \mathrm{C}$ temperature variation from the temperature at $10 \mathrm{~m}$ depth. This temperature criterion was found to be the most appropriate for estimating MLD from individual in situ profiles (de Boyer Montegut et al., 2004). A Krieging procedure then allows a limited filling of spatial gaps. This dataset has a sufficient spatial density to resolve interannual MLD variations in the TRIO region only after 2002, when the Argo network reaches its nominal resolution in the Indian Ocean.

In order to describe the thermocline depth interannual variability in the TRIO region and to evaluate the model, we use the Simple Ocean Data Analysis (SODA) version 2.2.4 oceanic re-analysis (Carton and Giese, 2005) obtained from http://sodaserver.tamu.edu/assim/SODA 2.2.4/. SODA uses an ocean model based on 
Geophysical Fluid Dynamics Laboratory MOM2 physics and assimilates all available in situ data (temperature and salinity profiles from the World Ocean Database, MBT, XBT, CTD, and station data, as well as additional hydrography, sea surface temperature, and altimeter sea level).

World Ocean Atlas 2009 (WOA09; Locarnini et al. 2009) climatological fields of temperature and currents are used in this study to evaluate the performance of the ocean model in reproducing the anomalous conditions after the 2006-07 IOD. We obtained temperature and current fields at $1^{\circ} \times 1^{\circ}$ grids at standard depth levels from http://www.nodc.noaa.gov/OC5/WOA09/pr woa09.html.

Additional in-situ observations used in this study were obtained during the Cirene cruise in early 2007 (See Vialard et al. 2009 for details). The Cirene cruise documented in-situ variability associated with tropical cyclones (Cuypers et al. 2013), the Madden Julian Oscillation (Vialard et al. 2008) and the Indian Ocean Dipole (Vialard et al. 2009) in the TRIO region. The Cirene cruise took place on the RV Suroit in January-February 2007. In the current paper, we will mainly use temperature data collected during several eXpandable Bathy Thermographs (XBT, most of the profiles down to $800 \mathrm{~m}$ ) sections, with a $50 \mathrm{~km}$ horizontal resolution, along the green and dashed lines on figure 1 . We will also use two high-resolution ( 2-3 profiles per hour) depth-time sections of temperature and salinity obtained during two long conductivity temperature depth (CTD) stations at $67^{\circ} 30^{\circ} \mathrm{E}, 8^{\circ} \mathrm{S}$ (CTD long station) from 14-26 January and 4-15 February 2007. Current measurements from two coupled $300 \mathrm{kHz}$ lowered acoustic Doppler current profilers (L-ADCP) were also acquired down to $\sim 1000 \mathrm{~m}$ at 6-hourly intervals at the long CTD stations. The Cirene cruise collected ocean profiles in the TRIO region in the aftermath of a strong IOD, which induced large upper ocean temperature, salinity and current anomalies (Vialard et al. 2009). We will compute temperature and salinity anomalies with respect to the January WOA2009 climatologies (Locarnini et al. 2010). Current anomalies will be computed with respect to geostrophic currents derived from the same climatology using the thermal wind relation, with a reference level at $1000 \mathrm{~m}$.

\subsection{Methods}

Previous studies have used slightly different definitions of the TRIO region (e.g. Hermes and Reason. 2008 used the [45-75 ${ }^{\circ} \mathrm{E}, 10^{\circ} \mathrm{S}-5^{\circ} \mathrm{S}$ ] region; Yokoi et al. 2008 and Tozuka et al. 2010 used the $\left[50-75^{\circ} \mathrm{E}, 10^{\circ} \mathrm{S}-5^{\circ} \mathrm{S}\right]$ region; Foltz et al. used the $\left[50-75^{\circ} \mathrm{E}, 12^{\circ} \mathrm{S}-5^{\circ} \mathrm{S}\right]$ region; Vialard et al. 2009 and Jayakumar et al. 2011 used the [60-90 ${ }^{\circ} \mathrm{E}, 10^{\circ} \mathrm{S}-5^{\circ} \mathrm{S}$ ] region). Depending on the objectives of the study (intraseasonal, seasonal or interannual SST variability), a slightly different choice of the box can be justified. Since our study focuses on mechanisms controlling interannual SST variations, we have defined the TRIO region as the $\left[50^{\circ} \mathrm{E}-80^{\circ} \mathrm{E}, 5^{\circ} \mathrm{S}-12^{\circ} \mathrm{S}\right]$ box. The observational analysis of Xie et al. (2002) shows maxima in the interannual SST variability and the correlation between interannual SST and thermocline depth anomalies in this region (their figure 1). The qualitative results of our heat budget analysis are however insensitive to the choice of different TRIO regions defined in the literature.

All of the results below are based on monthly averages of 5 day-averaged model outputs. Similarly, all observational data are also converted to monthly files for long-term analyses. We compute interannual anomalies for all variables by first subtracting the seasonal cycle from the interannual data, and then applying a 3-month running filter to remove subseasonal signals. In the rest of the paper, we will denote SST interannual anomalies computed in such a way as SSTAs, except in equation (1), where they are referred to as $T$ (while $\bar{T}$ designates the SST mean seasonal cycle). 
In section 5, we will separate signals associated with the IOD from those associated with EI Niño. The IOD amplitude is estimated as the average September-November Dipole Mode Index (Saji et al. 1999), defined as the normalized difference between SSTA in the [50$\left.70^{\circ} \mathrm{E}, 10^{\circ} \mathrm{S}-10^{\circ} \mathrm{N}\right]$ and $\left[90-110^{\circ} \mathrm{E}, 0-10^{\circ} \mathrm{S}\right]$ boxes. El Niño amplitude is estimated from the average November-January Niño3.4 index, i.e. the standardized average SSTA in the $\left[170^{\circ} \mathrm{W}-120^{\circ} \mathrm{W}, 5^{\circ} \mathrm{N}-5^{\circ} \mathrm{S}\right]$ region. Since the IOD tends to co-occur with El Niño, these indices are positively correlated (correlation of 0.66 over the 1984-2007 period) and a simple regression analysis is not sufficient to isolate the intrinsic variability associated with each mode. As in previous studies, we will use a partial regression analysis (e.g. Yamagata et al. 2004, Yu et al. 2005, Rao and Behera 2005, Keerthi et al. 2013, Currie et al. 2013). Partial regression (or correlation) of a variable $X$ to $Y 1$, independent of $Y 2$, is obtained from the regression of $X^{\prime}$ onto $Y 1^{\prime}$ ', where the prime refers to the residuals of the linear regression to $Y 2$ (i.e. $X^{\prime}=X-a Y 2$ where $a$ is the linear regression coefficient of $X$ to $Y 2$ ). Partial regression to the NDJ Niño3.4 index (Y1) and to the SON DMI index (Y2) are performed for oceanic variables and tendency terms at various lags $(X)$, starting in JJA before the peak of IOD and finishing in JJA after the peak of ENSO.

Since our $14^{\circ}$ resolution ocean model experiment is too short (1993-2007, i.e. only 15 years) to apply the ENSO/IOD regression analysis with confidence, we will use the longer $2^{\circ}$ resolution experiment (1958-2007). In this experiment, interannual surface shortwave fluxes are included only from 1984 onward, when the ISCCP product becomes available (see Brodeau et al. 2010). Since surface shortwave fluxes are an important process driving the ENSO response in the Indian Ocean (e.g. Klein et al. 1999, Lau and Nath 2000), we restrained the partial regression analyses to the 1984-2007 period (24 years). This 24-year period includes four positive IOD events $(1987,1994,1997,2006)$, five negative IOD events $(1989,1992,1996,1998,2001)$; six El-Niño events (1986-87, 1991-92, 1993, $1997-$ 98, 2002, 2004) and four La Niña events (1984, 1988, 1996, 1998-99) (Hong et al. 2008, Meyers et al. 2007)

\subsection{Model and observation-based mixed layer heat budget}

Following Vialard et al (2001), we used a simplified temperature tendency equation to estimate the contributions of various processes to mixed layer temperature variability:

$$
\partial_{t} T=\underbrace{\frac{Q_{S}(1-f(-h))+Q^{*}}{\rho_{0} C_{p} h}}_{(a)} \underbrace{-U \partial_{x} T-V_{y} T}_{(b)}+\underbrace{R}_{(c)}
$$

Here $T$ is temperature averaged in the mixed layer (i.e. the SST), $Q_{S}$ is the surface shortwave flux; $Q^{*}$ the sum of the longwave, latent and sensible fluxes; the $f(-h)$ function describes the fraction of shortwave fluxes penetrating the mixed layer, following the double exponential rule corresponding to type I water in the Jerlov (1968) classification; $\rho_{0}$ is the seawater density; $C_{p}$ the seawater volumetric heat capacity; $h$ the mixed layer depth, $u$ and $v$ the mixed layer average currents. Term (a) represents the effect of atmospheric heat fluxes on the mixed layer. Term (b) represents the effect of lateral advection by mixed layer currents. Term $\mathrm{R}$ in (c) is dominated by the contribution of vertical ocean processes (entrainment, vertical mixing and vertical advection), with other contributions (e.g. from inhomogeneities within the mixed layer) playing a small role (Vialard et al. 2001). Since we focus on interannual anomalies in this paper, we will usually refer to interannual anomalies of equation (1) computed for each term of the equation as explained in section 2.3.

In the ocean model, the mixed layer $h$ is defined as the layer in which density is within 0.01 $\mathrm{kg} \mathrm{m}^{-3}$ of the surface density. Some terms of the residual $\mathrm{R}$ (effect of vertical mixing and 
vertical advection at the bottom of the mixed layer) are computed explicitly online while the entrainment term can only be obtained as a residual due to the time-discretization of the NEMO model (see Vialard et al. 1998 for more details). All other terms in equation (1) are computed online explicitly during the simulation and stored as 5-day averages.

For the observational analysis, the left hand side of equation (1) is computed from TropFlux SST. Term (a) is computed using a combination of TropFlux surface heat fluxes (for $Q_{S}$ and $\left.Q^{*}\right)$ and the Keerthi et al. (2013) interannually varying mixed layer depth. Using Keerthi et al. (2013) MLD limits the observation-based heat budget computation to the post-2002 period. As we will see in section 3, the NEMO simulation accurately reproduces the observed MLD seasonal cycle and interannual anomalies. We will hence use the modeled MLD in order to obtain the observationally-derived upper ocean heat budget over the whole 1993-2007 period. Term (b) is computed using OSCAR surface currents for $u$ and $v$ and a centered difference of TropFlux SST over a distance of $2^{\circ}$. Term (c) is obtained as a residual from the observational estimates, and it contains both the contribution of vertical ocean processes and any error in the computation of the other terms.

While the analysis of interannual anomalies of equation (1) is useful to identify the dominant terms in the SSTA balance, Santoso et al. (2010) pointed out that it does not distinguish processes that contribute to the growth of SSTAs (i.e. $\partial_{t}\left|T^{\prime}\right|>0$ ) from those that induce decay. For this purpose, Santoso et al. (2010) multiplied interannual anomalies of equation (1) by $T$, leading to an equation for SSTA variance:

$$
1 / 2 \partial_{t}\left(T^{\prime 2}\right)=T^{\prime} \underbrace{\left(\frac{Q_{\mathcal{S}}(1-f(-h))+Q^{*}}{\rho_{0} C_{p} h}\right)}_{(a)}+T \underbrace{\left(-\omega \theta_{x} T-V \partial_{y} T\right)^{\prime}}_{(b)}+\underbrace{T^{\prime} R}_{(c)}
$$

The average values of the interannual anomalies of each tendency term in (1) multiplied by $T$ hence provide covariances between the tendency terms and SSTA and indicate whether the tendency terms contribute to the growth or decay of SSTA variance. We will call this technique Temperature Variance Budget (TVB) and use it for understanding the seasonal cycle of SSTA variance. Indeed, the mean seasonal cycle of equation (2) will provide an estimate of which processes contribute to the seasonal cycle of SSTA variance.

\section{Observed and Modeled variability in the TRIO region.}

In this section, we will first briefly evaluate the model seasonal cycle in the TRIO region and compare the seasonal heat balance to those from previous studies (Foltz et al. 2010, Halkides and Lee 2011, Yokoi et al. 2012). We will then evaluate the interannual variability of the model in the TRIO region using gridded products and in-situ data from the Cirene cruise.

\subsection{Seasonal cycle}

The model qualitatively reproduces the annual cycles of thermocline depth and sea level (Figure 2a), though there is a 1-2 month lead compared to observations, which display a minimum in May-June and maximum in October-November. The model also reproduces the phase locking of interannual thermocline depth anomalies to the seasonal cycle, with the largest anomalies from October to May (Figure 2b). The model also correctly simulates a 
flat seasonal cycle of the amplitude of interannual SST anomalies (Figure 2c) compared to the amplitude of the seasonal cycle of thermocline depth anomalies (Figure 2b). The model accurately reproduces the SST seasonal cycle (Figure 3a), with maximum temperature in early March-May $\left(\sim 29^{\circ} \mathrm{C}\right)$ and minimum in late June-August $\left(\sim 26.5^{\circ} \mathrm{C}\right)$. MLD in the model and observations (Figure $3 b$ ) is shallow (20-25 m) from December to May, but starts deepening in June with the southwest monsoon onset and reaches $\sim 50 \mathrm{~m}$ in AugustSeptember. The modeled and observationally derived surface zonal currents agree well, with a $\sim 15 \mathrm{~cm} \mathrm{~s}^{-1}$ westward current (the South Equatorial Current, e.g. Schott and McCreary 2001) throughout the year except in February-April, when it weakens (Figure 3c). In contrast, the meridional currents show a stronger bias compared to observationally derived fields. Both the model and OSCAR display strong southward flow associated with Ekman transport during the Southwest monsoon. However, the model meridional currents are stronger than those from the OSCAR and Lumpkin and Garzoli (2005, not shown) climatologies, with southward currents $\sim 10 \mathrm{~cm} \mathrm{~s}^{-1}$ during July-August compared to $\sim 5 \mathrm{~cm} . \mathrm{s}^{-}$ 1 in observations. Despite a $\sim 25 \mathrm{~W} \mathrm{~m}^{-2}$ offset, the annual cycles of the flux components (Figure $3 d$ ) agree well between the model and observations, with a large heat gain throughout the year except during the Southwest monsoon, when the strong winds and clouds induce larger latent heat losses and smaller downward shortwave fluxes.

Figure $3 e$ displays the seasonal surface layer heat balance derived from the model and observations (de Boyer et al. (2004) MLD is used here). The SST increases from August to March, and then decreases from April to July. There is a constant offset in the atmospheric forcing term between the model and observations (in line with a similar offset in net surface fluxes in figure $3 d$ and MLD underestimation in the model in winter and spring), but in both cases surface heat fluxes are the primary driver of the seasonal SST cycle, in agreement with Foltz et al. (2010), Halkides and Lee (2011) and Yokoi et al. (2012). The modeled and observed lateral advection terms agree well and indicate a warming tendency during JuneNovember. Total advection is dominated by meridional advection during the Southwest monsoon period (not shown) in accordance with stronger meridional currents during that season. In both the model and in observations, the cooling by vertical oceanic processes is at a minimum during late boreal summer (Figure $3 \mathrm{e}$ ). The seasonal amplitude of this process is larger in the observations compared to the model. Our analysis is in good agreement with those of Foltz et al. (2010) and Yokoi et al. (2012), who suggested a dominant role of air-sea fluxes, with lateral advection playing a secondary role, while Halkides and Lee (2011) suggest a larger contribution from horizontal advective processes.

\subsection{Interannual variations}

The generally good agreement between our model output and the results of previous studies suggests that our model successfully simulates the processes of seasonal SST variations in the TRIO region. This is a prerequisite for investigating the processes at interannual timescales. Another prerequisite is that the model reproduces well the observed interannual variability. In this section, we therefore first use observations to evaluate longterm interannual variations in the TRIO region simulated by the model. The validation is followed by a smaller-scale evaluation of the model's upper ocean anomalies in the TRIO region in the aftermath of the 2006 IOD based on observations from the Cirene cruise.

Figure 4 summarizes the modelled and observed interannual anomalies in the TRIO region. The two largest positive IOD events occur in late 1997 and 2006 (Meyers et al. 2007). Both tend to be associated with positive sea level (deep thermocline), deep mixed layer and warm SST anomalies, and are followed by anomalous westward currents. The sign of the net surface flux anomalies is not consistent across the two events. Heat flux is the most uncertain variable: the correlation between the modeled and observed monthly interannual anomalies is only 0.66 , and the model tends to overestimate the observed interannual heat flux anomalies by $\sim 40 \%$. For all other variables (SST, MLD, zonal and meridional currents, 
sea level) there is good agreement with the observations in terms of phase (correlations above 0.8 ) and amplitude (less than $20 \%$ mismatch) of modelled monthly interannual anomalies, lending some confidence to the model's ability to simulate interannual variability in the TRIO region.

The Cirene cruise period is highlighted with grey shading in figure 4 . It coincided with the second strongest remotely sensed sea level anomaly $(\sim 0.25 \mathrm{~m})$ in the TRIO region since 1994 (Figure 4e). Figure 5 shows a map of modelled and observed sea level and current anomalies during the first leg of the Cirene cruise (14-26 January 2007). This map shows a typical sea level pattern following a positive IOD event (e.g. Webster et al. 1999). The positive sea-level anomaly generated south of the equator in the eastern Indian Ocean during the IOD's peak in boreal fall 2006 travelled westward due to planetary wave dynamics and reached the TRIO region in January 2007 (e.g. Vialard et al. 2009). In the meantime, the downwelling equatorial Kelvin wave forced during the peak of the IOD reflects as a downwelling Rossby wave along the coast of Java and Sumatra, resulting in negative off-equatorial sea level anomalies and eastward current anomalies in the eastern Indian Ocean. The southern end of the cruise and the long station site (see the black square in figure 5) sampled the regions of strongest sea level anomalies. Despite some differences in the detailed location of the maxima, the broad sea level pattern in the observations and model agree.

Figure 6 displays subsurface temperature anomalies derived from the model and from Cirene XBT sections (along the sections marked 2 and 3 on figure 5). The model and observations display qualitatively similar patterns, but the model underestimates the amplitude of the warming signal (up to 6 or $7^{\circ} \mathrm{C}$ in the observations while the model does not exceed $3^{\circ} \mathrm{C}$ ). The discrepancy can be attributed partially to the fact that the model's thermocline is not as sharp as the observed climatological thermocline so that the model's vertical thermocline displacements result in temperature changes that are too weak.

Figure 7 shows the observed and modelled anomalies at $8^{\circ} \mathrm{S}, 67^{\circ} \mathrm{E}$ averaged over the first leg of the Cirene cruise (14-26 January 2007). Consistent with figure 6 , the amplitude of the modelled warm anomaly in the thermocline is about half as strong as the observed anomaly. Finally, observations indicate a $0.3 \mathrm{~ms}^{-1}$ eastward anomaly of the South Equatorial Current that extends well below the surface (still $\sim 0.2 \mathrm{~ms}^{-1}$ at $600 \mathrm{~m}$, cf Vialard et al. 2009). The model reasonably simulates the baroclinic structure of the current anomaly, but again underestimates the amplitude, especially close to the surface.

In this section, we saw that the model long-term evolution agrees well with most observed interannual anomalies in the TRIO region in terms of sea level, MLD, SST and surface currents, but that the agreement is less favourable for surface heat fluxes. While largescale sea level and currents agree reasonably well with observations in the aftermath of the 2006 IOD, comparisons with Cirene cruise data reveal that the model tends to underestimate subsurface temperature and current anomalies significantly. In the discussion section we discuss the potential impacts of these biases on our results.

\section{Processes controlling seasonality of SSTA amplitude}

In this section, we use the Temperature Variance Budget (TVB) analysis technique of Santoso et al. (2010) and described in section 2.4 to investigate the mechanisms driving the seasonality of the amplitude of SST interannual anomalies in the TRIO region.

Figure 2c shows that there is no clear seasonal phase locking of SST interannual anomalies (the maximum of the SSTA seasonal cycle is only 1.5 times larger than the 
minimum, compared to 2.5 times for anomalies of D20). As a result, the observed and modelled temperature variance tendencies (black lines in figure 8) show very weak seasonalities, though the model displays a stronger seasonal cycle of SSTA variance tendency, in agreement with figure 2c. The decomposition of the total variance tendency into its various components reveals the causes of the weak SSTA seasonality. A common feature of the TVB analyses in the model and observations in figure 8 is the out of phase relationship between atmospheric forcing and the sum of lateral advection and vertical oceanic processes. Vertical oceanic processes tend to increase SSTA variance from roughly December to June, while lateral advection tends to increase SSTA variance from July to November. The atmospheric forcing variance tendency is relatively flat in the observations compared to the model analysis and tends to damp the growth of SSTA throughout. It is therefore the different seasonalities of vertical oceanic processes and lateral advection that produce a relatively flat seasonal cycle of SSTA amplitude. Below, we explain the seasonal cycle from each physical process.

In observations, air-sea fluxes feed back negatively onto SSTA anomalies at a nearly constant rate throughout the year (figure 8a). This results from several factors (figure 9a). Positive SST anomalies induce more clouds and less shortwave radiation in boreal winter and spring (i.e. when the cloud coverage is strongest), but this increase in the shortwave negative feedback is compensated by a positive feedback from longwave radiation (the greenhouse effect of clouds) and latent heat fluxes (largely through a reduction of surface winds, Wu et al. 2008, Du et al. 2009). On the other hand, the latent heat flux negative feedback is strongest in boreal summer in the observations (figure 9a) due to the strong winds of the southwest monsoon. In the model, the seasonality of the shortwave feedback is realistic, but a positive SST anomaly does not lead to enhanced evaporation in boreal summer (Figure 9b). This results in a larger (and possibly spurious) seasonal cycle of the air-sea flux feedback in the model compared to observations (Figure 9). In any case, both the observations and the model indicate that the phase opposition between the subsurface processes and lateral advection contributes significantly to the small seasonal cycle of SSTA variance in figure 8.

Vertical oceanic processes contribute most to the seasonal increase of SSTA variance from December to June (figure 8). The effect of vertical processes is modulated by the mean thermocline depth (with a larger effect on the surface when the thermocline is shallow) and by the amplitude of the subsurface variability (larger anomalies in the thermocline having a stronger influence on the surface). The thermocline is shallowest from March to July (figure 2a). On the other hand, the largest interannual anomalies in thermocline depth occur between October and April (figure 2b), shortly after the peak of IOD and ENSO events that typically generate them (Yu et al. 2005). The deeper thermocline and its weaker variability from July to November minimize the impact of oceanic vertical processes on SSTA variability during those months (figure 8 ). The large contribution of vertical processes to SSTA variance from December to June is hence the result of both large interannual variability and shallow mean thermocline depth. Figure 8 shows that lateral advection contributes strongly to the SSTA variance in the TRIO region during late boreal summer and early fall. In agreement with the seasonal cycle (section 3.1; Foltz et al. 2010, Halkides and Lee 2011, Yokoi et al. 2012), the meridional component dominates the lateral advection term in the observations and in the model (see figure 8). We will hence focus on the meridional component in order to explain the seasonal evolution of the lateral advection contribution to SSTA. The decomposition of the anomalous meridional advection $-\left(v \partial_{y} T\right)^{\prime}=-v \partial_{y} T-\nabla \partial_{y} T^{\prime}-v \partial_{y} T^{\prime}$

(where the overbar designates the seasonal cycle and the prime designates interannual anomalies) shows that the ${ }^{-V \partial_{y} \bar{T}}$ term dominates from July to November in the model and observations (Figure 10a,b). Figures 10c and 10d decompose the seasonal cycle of this term. The climatological meridional SST gradient 


\section{$\partial_{y} \bar{T}$}

peaks in August-September (Figure 10d), whereas meridional current interannual anomalies $v$ are weak during August-September and increase afterward. These two factors explain the maximum in the $-V \partial_{y} \bar{T}$ term during September to October (Figure 10a, b). Meridional advection hence contributes most strongly to SSTA generation in the TRIO region during late boreal summer and fall because of a larger climatological meridional SST gradient and larger meridional current anomalies during these seasons.

In this section, we have explained why the seasonal variation of SSTA amplitude is relatively weak in the TRIO region. Despite a peak in SSTA production by vertical oceanic processes from February to May, there is a large increase in SSTA generation by lateral advection anomalies during the opposite phase of the seasonal cycle (August to September). Since atmospheric forcing generally opposes the SSTA growth, the phase opposition between vertical and lateral oceanic processes (both acting to increase SSTA variance) results in a relatively flat seasonal cycle of SSTA variance in the TRIO region. The role of atmospheric forcing (ie. to damp SSTA growth) discussed in this section should be interpreted carefully. First, there is a large mismatch between observations and model simulations. Secondly, the role of atmospheric fluxes differs in relation to various interannual processes (eg. positive and negative IOD, EI Nino and La Nina, etc), and the results presented in this section do not separate these effects (Klein et al. 1999, Xie et al. 2002). In the following section, we quantify the contributions of various processes to IODand ENSO-induced SSTA variations in the TRIO region.

\section{Signatures of the IOD and EI Niño in the TRIO}

In the previous section, we explored the physical processes driving SSTA evolution in the TRIO region, irrespective of whether they are linked to the remote signature of ENSO or to the IOD. In this section, we use partial regression analysis to disentangle the influences of ENSO and IOD on SST evolution in this region (see section 2.3). The $1 / 4^{\circ}$ model simulation is too short (15 years) to use the partial regression method, so we use the global experiment at a lower spatial resolution but over a longer period (1984-2007, 24 years). The two experiments exhibit similar results over their common period (not shown). Since observational records are also too short for the partial regression analysis, we will focus on the model results in this section. Several studies (Rao and Behera 2005, Yu et al. 2005) indicate that ENSO has a stronger impact between $10-15^{\circ} \mathrm{S}$, while the IOD influence peaks in the $5-10^{\circ} \mathrm{S}$ band. We therefore repeated the analysis for these two latitude ranges and found very similar results to those obtained using our TRIO box $\left(50-80^{\circ} \mathrm{E}, 5-12^{\circ} \mathrm{S}\right)$.

Figure 11 illustrates the evolution of key variables (SST, surface heat fluxes, sea level anomaly, surface currents and mixed layer heat budget) in the TRIO region associated with IOD and ENSO. The partial regression technique that we use is linear (i.e. it does not account for asymmetries between positive and negative phases), so for simplicity we show results for the positive phase of an IOD event (left column) and an EI Niño (right column). Figures 12 and 13 provide a basin-scale view of IOD- and ENSO-induced changes in these key variables. Figure 12 shows the typical IOD pattern (e.g. Saji et al. 1999), with cold SST anomalies at the Sumatra coast in SON (Figure 12e) and anomalous easterlies in the Central Indian Ocean (Figure 12b). This wind pattern drives Ekman convergence and deepens the thermocline on the southern side of the equatorial easterly anomaly in SON (e.g. Webster et al. 1999). The associated sea level anomaly then propagates westward into the TRIO region (Figure 12c), where it reaches a maximum in DJF (Figure 11b). As a result, IOD-induced SST anomalies grow from August to November and decay from January to April (Figure 12d-f and figure 11a). As previously described (e.g. Xie et al. 2009, 
Currie et al. 2013), the SST signature of ENSO appears later (Figure 13d-f). ENSO-induced SST and sea level anomalies in the TRIO region grow from December to March and decay from May to August (Figure 11d-e).

The IOD SSTA increases during boreal fall. During this season, the largest contributor to the SSTA growth is lateral advection, mainly through its meridional component (Figure 11c). As we saw in section 4 , the meridional advection term is dominated by the $-\sqrt{ } \partial_{y} \bar{T}$ term. The anticyclonic flow around the positive sea level anomaly in the eastern half of the TRIO box induces an anomalous southward flow in most of the TRIO box (vectors on figure 12b). This, combined with the presence of a strong climatological SST meridional gradient (colors on figure 14a), with warm water to the north and colder water to the south, results in a positive tendency of SSTA. Although sea level anomalies in the region induce variations in the strength of the south equatorial current (Fig 12b), the relatively small zonal climatological SST gradient in the TRIO region results in a smaller contribution from zonal advection. Atmospheric forcing also contributes to the initial IOD-induced SSTA growth ${ }^{1}$ in the TRIO region (Figure 11c), mostly through reduced evaporation (not shown).

After reaching a peak in November-December, the IOD-induced SSTA in the TRIO region begins to decrease (Figure 11a), with the largest contributor to the decline being a negative surface heat flux anomaly that tends to cool SST (figure 11c and figure $12 \mathrm{e}, \mathrm{f}$ ). This feedback is associated mainly with the development of deep atmospheric convection and the resultant decrease in surface shortwave radiation by clouds (not shown, Xie et al. 2002). This negative feedback from the surface heat flux largely overwhelms the warming effect of meridional advection and vertical oceanic processes (Fig. 11c). The warming signal associated with vertical oceanic processes in boreal winter can be attributed to a westward-propagating thermocline depression forced by wind-driven Ekman pumping. While this thermocline depression in the TRIO region appears in boreal fall, it only influences vertical oceanic processes in boreal winter, probably because of the seasonal cycle of thermocline depth, which is deepest in September-November (Figure 2a). As a result, vertical oceanic processes do not contribute to the initiation of the SST warming but only act to maintain the SST anomalies associated with the IOD by opposing the cooling driven by the increased cloudiness (figure 11c).

The El Niño-induced warming in the TRIO region grows during DJFM and reaches its maximum around April (Fig 11d). The largest term contributing to the initiation of the warming is the atmospheric forcing (Figure 11f) through increased heat fluxes into the ocean (Figure 11d). The positive heat flux anomalies are driven largely by decreased cloudiness (not shown), consistent with hypotheses of remote El Niño forcing on the Indian Ocean (e.g. Klein et al. 1999, Lau and Nath 2000). Oceanic contributions from lateral advection and vertical processes nearly cancel during the initial stages of the ENSO SSTA development. Lateral advection indeed opposes the surface-flux induced warming, with roughly equal contributions from zonal and meridional advection, while vertical processes contribute to the warming. The contribution of lateral advection to ENSO-induced SST warming in the TRIO region is dominated by the $-\square \partial_{x} T^{\prime}-\nabla \partial_{y} T$ term (not shown). Figure $14 \mathrm{~b}$ shows the causes of the cooling tendency from advection: the Ekman-induced meridional divergence that is the main cause of the shallow thermocline in the TRIO region also advects the SSTAs out from the TRIO region. The ENSO induced sea-level anomaly in the TRIO region develops later than the IOD-induced anomaly and peaks in MAM. The later peak is probably due to the fact that ENSO-induced sea level anomalies develop farther south than those associated with the IOD (figures 12 and 13; also see Yu et al. 2005, Rao and Behera 2005) and hence propagate slower because of the phase speed of planetary

\footnotetext{
${ }^{1}$ We will discuss the apparent contradiction with results from section 4 in section 6.
} 
waves decreases with latitude. As for the IOD, vertical processes become a dominant term in ENSO-induced SSTA anomaly growth, but only in March-May. They hence do not initiate the ENSO-induced SST anomalies in the TRIO region, but act to maintain them into boreal spring and summer as suggested by Xie et al. (2009).

From March-April onward, the main balance is clearly between the atmospheric forcing and vertical oceanic processes (Figure 11f), with lateral advection quickly becoming small compared to these terms. The atmospheric forcing damps the SST anomaly due to increased deep atmospheric convection and an associated reduction in downward surface shortwave radiation (Xie et al. 2002). From April onwards, the sea level anomaly decays, as does the anomalous warming due to oceanic vertical processes. As a result, the negative feedback from air-sea fluxes takes over and the ENSO induced SSTA decays.

Figure 15 provides a summary of the processes that govern the rise (approximately ASON for the IOD and DJFM for ENSO) and fall (JFMA for the IOD and MJJA for ENSO) of SST interannual anomalies in the TRIO region. The IOD and ENSO have comparable SST $\left(\sim 0.2^{\circ} \mathrm{C}\right)$ standard deviations over the TRIO region, but the IOD signal tends to peak earlier (November-December) than that associated with ENSO (April-May, figure 15). The IOD SSTA initial growth during ASON is mostly the result of southward advection of warmer water (figure 15a), while vertical oceanic processes only act to maintain the IOD-induced anomaly at a later stage, when the negative feedback of air-sea fluxes starts to damp the SSTA strongly (figure 15a). During the ENSO-induced increase in SSTA, atmospheric forcing and vertical processes contribute almost equally, while lateral advection opposes the SSTA change. As for the IOD, vertical oceanic processes peak later, opposing the negative feedback from air-sea fluxes during the ENSO-induced SSTA decay. For both ENSO and the IOD, vertical processes act to maintain the SSTA rather than initiate it.

\section{Summary and Discussion}

\subsection{Summary}

Several studies suggest that the thermocline ridge of the Indian Ocean (TRIO) has important climatic impacts (Jury et al. 1999; Xie et al. 2002, Vecchi and Harrison 2004; Izumo et al. 2008, Annamalai et al. 2005, Vialard et al. 2009), providing an incentive for several recent studies on the seasonal (Hermes and Reason. 2008, Yokoi et al. 2008, Yokoi et al. 2009, Foltz et al. 2010, Halkides and Lee. 2011) and interannual variations (Tozuka et al. 2010, Yokoi et al. 2012, Trenary and Han. 2012) in this region. However, few studies have investigated the processes responsible for SST interannual anomalies in the TRIO region, with Yokoi et al. (2012) providing the only dedicated study on the topic. Our emphasis is hence to analyse the processes controlling the interannual variability of SST in the TRIO region using observations and OGCM output. The focuses of this article are twofold: first, to investigate the weak seasonality of SSTA in spite of a marked phase locking of thermocline depth interannual anomalies to boreal winter. Secondly, to isolate the roles of the IOD and ENSO in modulating SSTAs in the TRIO region.

Extensive evaluation of our ocean model revealed that it has a realistic mean seasonal cycle in the TRIO region, with the exception of southward meridional currents that are too strong. Our surface layer seasonal heat budget analysis is in good agreement with previous studies (Hermes and Reason. 2008, Yokoi et al. 2008, Foltz et al. 2010, Halkides and Lee. 2011). The model reproduces well the observed interannual anomalies of SST, mixed layer depth, sea level, and currents but shows more disagreement with observed surface heat fluxes. The model also reproduces qualitatively the main anomalies observed after the 2006 IOD in the TRIO region, though with somewhat weaker amplitude. 
While there is a clear phase locking of interannual thermocline depth anomalies to the seasonal cycle, with a clear maximum in NDJFM (Figure 2b, Tozuka et al. 2010), there is no such marked phase locking of SSTA anomalies. Previous studies (e.g. Xie et al. 2002, Yokoi et al. 2012) insisted on the importance of vertical oceanic processes, which tend to promote larger SSTA variance from December to May, due to the combination of larger thermocline depth perturbations during December-February and a shallow mean thermocline during March-May. In contrast, lateral advection, mainly associated with meridional advection of the climatological SST gradient by anomalous currents, tends to increase SSTA variance from July to November, when the meridional SST gradient is largest. As a result of the phase opposition between the seasonal cycle of vertical processes and lateral advection, there is no obvious peak in SSTA amplitude in boreal winter, as previously noted for heat content anomalies. Air-sea fluxes generally tend to provide a negative feedback to SSTA growth.

This is, as far as we know, the first study that analyses separately the processes responsible for IOD- and ENSO-induced SSTAs in the TRIO region. The IOD and ENSO have comparable SST $\left(\sim 0.2^{\circ} \mathrm{C}\right)$ and SLA $(\sim 0.06 \mathrm{~m})$ standard deviations over the TRIO region, but the IOD signals tend to peak earlier (November-December) than those associated with El Niño (around April-May). Another explanation of the relatively flat seasonal cycle of SSTA in the TRIO region is hence that IOD- and ENSO-induced SST anomalies occur at different times of the year (roughly from August to April for the IOD and from December to August for ENSO). The IOD SSTA initial growth during ASON is mostly the result of southward advection of warmer water, while vertical oceanic processes only act to maintain the IOD-induced SSTA against the negative feedback from air-sea fluxes at a later stage (JFMA, Figure 15a). Increased downward surface heat fluxes contribute to the growth of the ENSO-induced SSTAs, while lateral advection and vertical processes vary out of phase so that the sum of oceanic processes contributes very little (figure 15b). During the decay phase of ENSO-induced SSTA in MJJA, oceanic vertical processes peak, helping to maintain the SST anomaly against the negative heat flux feedback.

\subsection{Discussion}

The analysis of figure 8 suggests that air-sea fluxes are a negative feedback on the development of SSTA anomalies in all seasons. Figures $11 \mathrm{f}$ and 15 on the other hand suggest a moderate contribution of air-sea fluxes to the initial growth of ENSO-induced SSTA anomalies in the TRIO region. There is hence an apparent contradiction between those two results. In practice, ENSO and IOD events often co-occur. In that case, the processes associated with the IOD demise (strong negative feedback from air-sea fluxes) and those associated with ENSO-induced SSTA growth (weaker positive contribution from air-sea fluxes) will contribute to the overall response in the TRIO region, since they occur at the same time of year (DJFM). Overall, the negative feedback from the surface heat flux tends to dominate. Hence, properly interpreted, there is no contradiction between the results of figures 8 and 11.

Several studies have emphasized the semi-annual cycle of thermocline depth in the TRIO region (e.g. Hermes and Reason 2008, Yokoi et al. 2009), but the model and observations in this study are dominated by the annual harmonic. There are two reasons for this apparent contradiction. First, semi-annual variability increases abruptly west of $70-80^{\circ} \mathrm{E}$ (e.g. Wang et al. 2001) and the domain we consider for our study is bounded on the west at $80^{\circ} \mathrm{E}$. In contrast, Hermes and Reason (2008) and Yokoi et al. (2009) both used $75^{\circ} \mathrm{E}$ as the eastern limit of their domain. Trenary and Han (2012) also report the sensitivity of the annual and semi-annual variability of the thermocline to the exact boundaries selected for the thermocline ridge region. Second, the World Ocean Atlas 2009 (Locarnini et al. 2010) product tends to produce larger semi-annual variability than the SODA re-analysis or the altimeter sea level (not shown). Because of the large zonal smoothing between gaps in the 
World Ocean Atlas 2009, we suggest that it is better to use a SODA- or altimeter-derived seasonal cycle in this region. Therefore, we point out that our conclusions from figures 8 , 11 and 15 remain qualitatively similar when we select the boxes from Hermes and Reason (2008) and Yokoi et al. (2009) rather than the one we used in that study.

Let us now discuss the potential influence of model biases on our results. The model thermocline is not as tight as in observationally derived climatologies. This may result in a model underestimation of the importance of vertical oceanic processes. The mean meridional currents are too large in austral winter, when compared to the OSCAR and Lumpkin and Garzoli (2005) (not shown) climatologies. However, this likely does not have a strong influence on our results, since we find that the main effect of meridional advection on SST interannual anomalies is through the advection of the climatological meridional SST gradient by current anomalies. Finally, the amplitudes of interannual anomalies in surface heat flux computed by the model are $\sim 40 \%$ too large and correlate only at 0.66 with the observations (Praveen Kumar et al. 2012). Although there is no relaxation to observed SST, the prescription of near-surface air temperature and humidity acts as an hidden relaxation" (de Boyer Montégut et al. 2007), leading to an excessive heat flux amplitude, and potentially an overestimation of surface heat flux effects in the model, which we discuss further below.

Nonetheless, there was generally good agreement between the model results and the observations. However, let us now focus on the disagreement we found between the two methods. In the seasonal SST tendency analysis, we found an equivalent contribution from vertical oceanic processes and lateral advection in the model, while the contribution from vertical processes was larger in observations. Since in the observations the vertical processes are calculated as a residual, we trust the model more, and suggest a larger contribution from vertical processes than what was suggested by Foltz et al. (2010). The model also suggests a larger role for atmospheric forcing in the seasonal cycle of SSTA variance compared to observations (Figure 8). We tend to trust the observed fluxes and suggest that vertical processes and lateral advection are the two main contributors to the seasonal cycle of SSTA variance.

Another potential limit of our study is that we have used only a 24-year time series for our partial regression analysis to separate the ENSO and IOD signals. However, we do obtain results that are consistent with other studies that used the same method over a longer period (e.g. Yu et al. 2005, Rao and Behera 2005, Keerthi et al. 2013, Currie et al. 2013). This suggests that our results on the processes that contribute to ENSO- and IOD-induced SSTA variations can be trusted.

Finally, our results are generally in agreement with past studies on the interannual variability of the TRIO region. For example, Murtugudde et al. (2000) and Du et al. (2009) showed that a combination of vertical oceanic processes and meridional advection contributed to the warming in the TRIO region following the 1997 IOD and EI Niño events, in agreement with our results. Xie et al. (2002) showed that thermocline depth anomalies are correlated at $\sim 0.6$ with SSTA in the TRIO region, with the interpretation that the subsurface and surface are connected through vertical oceanic processes. Santoso et al. (2010) did not focus on the TRIO region in particular, but their heat budget analyses also suggest an important role for vertical oceanic processes in driving SSTA in this region. Yokoi et al. (2012) found that SST warms in the TRIO region when the thermocline is anomalously deep, due to vertical oceanic processes, but also identified a contribution from meridional advection and a negative feedback from air-sea fluxes. Our results agree with these previous studies in designating oceanic (lateral advection and vertical processes) processes as a major cause for SST anomalies in this region, while air-sea fluxes in general tend to provide a negative feedback. The detailed analysis carried out for separating the IOD and ENSO signals, however, suggests that vertical oceanic processes 
(and horizontal advection to some extent as well, in the IOD case) rather act to maintain the SSTA after its initial development, in line with the ideas proposed by Xie et al. (2009). When focussing on the initial development of the SSTA anomaly associated with IOD, we clearly identify southward advection of warmer water by geostrophic current anomalies as an important cause. In contrast, the ENSO-induced initial warming is linked to the suppression of clouds over the Indian Ocean.

\section{Acknowledgements}

B. Praveen Kumar did this work while at CSIR-National Institute of Oceanography (CSIRNIO, Goa, India), with a research grant from the Council of Scientific and Industrial Research (CSIR, Govt. of India). Institut de Recherche pour le Développement (IRD, France) provided him a BEST" grant to support a one-year visit to Laboratoire d'Océanographie Expérimentation et Approches Numériques (LOCEAN, Paris). Jérôme Vialard and Matthieu Lengaigne are funded by Institut de Recherche pour le Développement (IRD). Matthieu Lengaigne provided his contribution to this paper while visiting the CSIR-National Institute of Oceanography (CSIR-NIO) in Goa, India. AnneCharlotte Peter ran the lower resolution global experiment that we used in this study. We thank the OSCAR project office for providing Oscar currents data and the National Oceanographic Data Center (NODC) from National Oceanic and Atmospheric Administration (NOAA) for providing the World Ocean Atlas dataset. TropFlux data is developed as a research collaboration between CSIR-National Institute of Oceanography (CSIR-NIO, India) and Laboratoire d'Océanographie Expérimentation et Approches Numériques (LOCEAN, Paris), and downloaded from http://www.loceanipsl.upmc.fr/tropflux/. We thank three anonymous reviewers who provided constructive comments on an initial version of the manuscript, and the editor for a quick review process.

This is NIO contribution number $\mathrm{xx}$, INCOIS contribution number 163, and PMEL contribution number 4108 .

\section{References}

Annamalai H., Liu P, Xie S-P, 2005: Southwest Indian Ocean SST variability: its local effect and remote influence on Asian monsoons. J. Clim., 18, 4150-4167.

Annamalai, H., R. Murtugudde, J. Potemra, S.P. Xie, P. Liu, and B. Wang, 2003: Coupled Dynamics over the Indian Ocean: Spring initiation of the zonal mode. Deep Sea Research II, 50, 2305-2330

Annamalai, H., H. Okajima, and M. Watanabe, 2007: Possible impact of the Indian Ocean SST on the Northern Hemisphere during EI Niño, J. Clim., 20, 3164-3189.

Barnier B., et al. 2006: Impact of partial steps and momentum advection schemes in a global ocean circulation model at eddy permitting resolution. Ocean Dyn., 56, 543567. doi:10.1007/s10236-006-0082-1

Bonjean, F., and G. S. E. Lagerloef, 2002: Diagnostic model and analysis of the surface currents in the tropical Pacific Ocean. J. Phys. Oceanogr., 32, 2938-2954.

Brodeau, L., Barnier B, Treguier A. M, Penduff T. Gulev S, 2010: An ERA40-based atmospheric forcing for global ocean circulation models. Ocean Model, 31, 88104. doi:10.1016/j.ocemod.2009. 10.005

Carton, J. A., and Giese, B. S., 2008. A reanalysis of ocean climate using simple ocean data assimilation (SODA). Monthly Weather Review, 136: 2999-3017.

Cassou, C., 2008, Intraseasonal interaction between the Madden-Julian Oscillation and the North Atlantic Oscillation, Nature, 455, 523-527. 
Currie, J., M. Lengaigne, J. Vialard, D. Kaplan, O. Aumont and O. Maury, 2013: Indian Ocean Dipole and El Niño/Southern Oscillation impacts on regional chlorophyll anomalies in the Indian Ocean, Biogeosciences, 10, 5841-5888

Cuypers, Y., X. Le Vaillant, P. Bouruet-Aubertot, J. Vialard, M. J. McPhaden, 2013: Tropical storm-induced near inertial internal waves during the Cirene experiment: energy fluxes and impact on vertical mixing, J. Geophys. Res., 118, 358-380.

de Boyer Montegut, C., Madec. G, Fischer. A. S, Lazar. A, ludicone, 2004: Mixed layer depth over the global ocean: an examination of profile data and a profile-based climatology. J Geophys Res, 109, doi: C12003. doi:10.1029/2004JC002378

De Boyer Montégut, C., J. Vialard, S.S.C. Shenoi, D. Shankar, F. Durand, C. Ethé and G. Madec, 2007, Simulated seasonal and interannual variability of mixed layer heat budget in the northern Indian Ocean, Journal of Climate, 20, 3249-3268.

Dee, D. P., et al. 2011: The ERA-interim reanalysis: configuration and performance of the data assimilation system. Q. J. R. Meteorol Soc, 137, 553-597. doi:10.1002/qj.828.

Du, Y., S-P. Xie, G. Huang, K. Hu, 2009: Role of Air-Sea Interaction in the Long Persistence of El Niño-Induced North Indian Ocean Warming. J. Clim., 22, 20232038., doi: http://dx.doi.org/10.1175/2008JCLI2590.1

Duvel, J. P., 2012: New topics and advances, oceans and air-sea interaction. In: Lau WKM, Waliser DE (eds) Intraseasonal variability in the atmosphere-ocean climate system, 2nd edn. Springer, New York, pp 513-530

Duvel, J. P., Vialard. J, 2007: Indo-Pacific Sea surface temperature perturbations associated with intraseasonal oscillations of the tropical convection. J. Clim. 20, 3056-3082

Fairall, C. W., Bradley. E. F, Hare. J. E, Grachev. A. A, Edson. J. B, 2003: Bulk parameterization on air-sea fluxes: updates and verification for the COARE algorithm. J Clim, 16, 571-591

Foltz, G. R., Vialard. J, Praveen Kumar. B, McPhaden. M. J, 2010: Seasonal mixed layer heat balance of the southwestern tropical Indian Ocean. J Clim., 23, 947-965

Graham, N. E, and Barnett. T. P, 1987: Sea surface temperature, surface wind divergence, and convection over the tropical oceans. Science, 238, 657-659

Halkides, D. J., and T. Lee, 2011: Mechanisms controlling seasonal mixed layer temperature and salinity in the southwestern tropical Indian Ocean. Dyn. Atmos. Oceans, 51, 77-93.

Harrison, D. E., Vecchi. G. A, 2001: January 1999 Indian Ocean cooling event. Geophys Res Lett, 28, 3717-3720

Hermes, J. C., and Reason. C. J. C, 2008: Annual cycle of the South Indian Ocean (Seychelles-Chagos) thermocline ridge in a regional ocean model. J Geophys Res, 113, C04035. doi:10.1029/2007JC004363

Hong, C.-C., M.-M. Lu, and M. Kanamitsu, 2008: Temporal and spatial characteristics of positive and negative Indian Ocean dipole with and without ENSO, J. Geophys. Res., 113, D08107, doi:10.1029/2007JD009151.

Huffman GJ, Adler RF, Arkin P, Chang A, Ferraro R, Gruber A, Janowiak J, McNab A, Rudolf B, Shneider U (1997) The Global Precipitation Climatology Project (GPCP) Combined Precipitation Dataset. Bull Amer Meteor Soc 78:5-20

Izumo, T., de Boyer Montégut C, Luo J-J, Behera. S. K, Masson. S, Yamagata. T, 2008: The role of the western Arabian Sea upwelling in Indian monsoon rainfall variability. J Climate 21:5603-5623

Large, W. G., Yeager S. G., 2004: Diurnal to decadal global forcing for ocean and sea-ice models: the data sets and flux climatologies. NCAR/TN-460 STR, 111.pp

Jayakumar, A., Vialard. J, Lengaigne. M, Gnanaseelan. C, McCreary. J. P, Praveen Kumar. $B, 2011$ : Processes controlling the surface temperature signature of the MaddenJulian Oscillation in the thermocline ridge of the Indian Ocean. Clim Dyn. doi: $10.1007 / \mathrm{s} 00382-010-0953-5$ 
Jury, M., B. Pathack, and B. Parker, 1999: Climatic determinants and statistical prediction of tropical cyclone days in the southwest Indian Ocean. J. Climate, 12, 1738-1755.

Keerthi, M. G., M. Lengaigne, J. Vialard, C. de Boyer Montégut and P.M. Muraleedharan, 2013: Interannual variability of the Tropical Indian Ocean mixed layer depth, Clim. Dyn., 40, 743-759.

Klein, S. A., Soden. B. J, Lau. N. C, 1999: Remote sea surface temperature variations during ENSO: evidence for a tropical atmospheric bridge. J Clim, 12, 917-932

Lau, N. C., Nath. M. J, 2000: Impact of ENSO on the variability of the Asian-Australian monsoons as simulated in GCM experiments. J Clim., 13, 4287-4309

Lengaigne, M., Haussman. U, Madec. G, Menkes. C, Vialard. J, 2012: Mechanisms controlling warm water volume interannual variations in the equatorial Pacific: diabatic versus adiabatic processes. Clim Dyn, 38, 1031-1046

Locarnini, R. A., Mishonov. A. V, Antonov. J. I, Boyer. T. P, Garcia. H. E, Baranova. O. K, Zweng. M. M, Johnson. D. R, 2010: World ocean atlas 2009, Volume 1: temperaturein: Levitus S (ed) NOAA Atlas NESDIS 68, US. Government Printing Office, Washington, DC, p 184

Lumpkin, R. and S. L. Garzoli, 2005: Near-surface Circulation in the Tropical Atlantic Ocean. Deep-Sea Res.I 52 (3), 495-518, 10.1016/j.dsr.2004.09.001.

Madden, R. A., and P. R. Julian, 1972: Description of global-scale circulation cells in the Tropics with a 40-50 day period. J. Atmos. Sci, 29, 3138-3158.

Madec, G., 2008: NEMO, the Ocean engine. Tech Rep, Notes de I'IPSL (27), ISSN 1288 1619, Université P. et M. Curie, 193 pp.

Masumoto, Y., and G. Meyers, 1998: Forced Rossby waves in the southern tropical Indian Ocean, J. Geophys. Res., 103, 27,589-27,602.

McCreary, J. P., Jr., P. K. Kundu, and R. L. Molinari, 1993: A numerical investigation of dynamics, thermodynamics and mixed-layer processes in the Indian Ocean, Prog. Oceanogr., 31, 181-244.

McPhaden, M.J., K. Ando, B. Bourlès, H.P. Freitag, R. Lumpkin, Y. Masumoto, V.S.N. Murty, P. Nobre, M. Ravichandran, J. Vialard, D. Vousden, and W. Yu, 2010: The global tropical moored buoy array. In Proceedings of the "OceanObs'09: Sustained Ocean Observations and Information for Society" Conference (Vol. 2), Venice, Italy, 21-25 September 2009, Hall, J., D.E. Harrison, and D. Stammer, Eds., ESA Publication WPP-306.

McPhaden, M. J. and M. Nagura, 2013: Indian Ocean Dipole interpreted in terms of Recharge Oscillator theory. Clim. Dyn., in press.

Meyers, G., P. McIntosh, L. Pigot, and M. Pook, 2007: The years of El Niño, La Niña, and interactions with the tropical Indian Ocean, J. Clim., 20, 2872-2880.

Murtugudde, R., J. P. McCreary, and A. J. Busalacchi, 2000: Oceanic processes associated with anomalous events in the Indian Ocean with relevance to 19971998, J. Geophys. Res., 105, 3295-3306.

Nidheesh, A. G., Lengaigne. M, Unnikrishnan. A. S, Vialard. J, 2012: Decadal and longterm sea level variability in the tropical Indo- Pacific. Clim Dyn. doi:10.1007/s00382-012-1463-4

Praveen Kumar, B., Vialard. J, Lengaigne. M, Murty. V.S.N, McPhaden. M.J, 2012: TropFlux: air-sea fluxes for the global tropical oceans-description and evaluation against observations. Clim Dyn, 38, 1521-1543

Praveen Kumar, B., Vialard. J, Lengaigne. M, Murty. V. S. N, McPhaden. M. J, Cronin. M, Pinsard. F, Gopala Reddy. K, 2012: TropFlux wind stresses over the tropical oceans: evaluation and comparison with other products. Clim Dyn. doi:10.1007/s00382-012-1455-4

Rao, S. A., and S. K. Behera, 2005: Subsurface influence on SST in the tropical Indian Ocean: Structure and interannual variability, Dyn. Atmos. Oceans, 39, 103-135.

Saji, N. H., Goswami. B. N, Vinayachandran. P. N, Yamagata. T, 1999: A dipole mode in the tropical Indian Ocean. Nature, 401, 360-363

Saji, N. H., S.-P. Xie, and C.-Y. Tam, 2006: Satellite observations of intense intraseasonal 
cooling events in the tropical South Indian Ocean, Geophys. Res. Lett., 33, L14704, doi:10.1029/2006GL026525.

Santoso, A., A. S. Gupta, and M. H. England, 2010: Genesis of Indian Ocean mixed layer temperature anomalies: A heat budget analysis. J. Clim., 23, 5375-5403.

Schott, F., and J. P. McCreary, 2001: The monsoon circulation of the Indian Ocean, Prog. Oceanogr., 51, 1-123.

Tozuka, T., T. Yokoi, and T. Yamagata, 2010: A modeling study of interannual variations of the Seychelles Dome. J. Geophys. Res., 115, C04005, doi:10.1029/2009JC005547.

Treguier, A. M., Barnier. B, de Miranda. A. P, Molines. J. M, Grima. N, Lmbard. M, Madec. G, Messaager. C, Teynaud. T, and Michel. S, 2011: An Du Du eddy permitting model of the Atlantic circulation: Evaluating open boundary conditions. J. Geophy. Res, 106. Doi: 10.1029/2000JC000376.

Trenary LL, Han W, 2012: Intraseasonal-to-interannual variability of South Indian Ocean sea level and thermocline: Remote versus local forcing. J Phys Oceanogr, 32, 602627

Uppala, S. M., et al, 2005: The ERA-40 re-analysis. Q J R Meteorol Soc, 131:2961-3012

Vecchi, G. A., and Harrison. D. E, 2004: Interannual Indian rainfall variability and Indian Ocean sea surface temperature anomalies. In: Wang C, Xie S-P, Carton JA (eds) Earth climate: the ocean-atmosphere interaction. American geophysical union, geophysical monograph 147, Washington DC, pp 247-260

Vialard, J. and P. Delecluse, 1998: An OGCM Study for the TOGA Decade. Part I : Role of Salinity in the Physics of the Western Pacific Fresh Pool. J. Phys. Oceanogr., 28, $1071-1088$.

Vialard, J., C. Menkes, J.-P. Boulanger, P. Delecluse, E. Guilyardi , M. J. McPhaden, and G. Madec, 2001: Oceanic mechanisms driving the SST during the 1997-1998 El Niño, J. Phys. Oceanogr., 31, 1649-1675.

Vialard, J., G. Foltz, M. McPhaden , J-P. Duvel and C. de Boyer Montégut, 2008: Strong Indian Ocean sea surface temperature signals associated with the Madden-Julian Oscillation in late 2007 and early 2008, Geophys. Res. Lett., 35, L19608, doi:10.1029/2008GL035238

Vialard J, Duvel J-P, McPhaden M, Bouruet-Aubertot P, Ward B, Key E, Bourras D, Weller $R$, Minnett $P$, Weill A, Cassou C, Eymard L, Fristedt T, Basdevant C, Dandoneau Y, Duteil O, Izumo T, de Boyer Monte'gut C, Masson S, Marsac F, Menkes C, Kennan S, 2009: Cirene: air sea interactions in the Seychelles-Chagos thermocline ridge region. Bull. Am. Met. Soc. 90, 45-61

Vialard, J., S.S.C Shenoi, J.P. McCreary, D. Shankar, F. Durand, V. Fernando and S.R. Shetye, 2009: Intraseasonal response of Northern Indian Ocean coastal waveguide to the Madden-Julian Oscillation, Geophys. Res. Lett., 36, L14605, doi:10.1029/2008GL037010.

Vialard, J., K. Drushka, H. Bellenger, M. Lengaigne, S. Pous and J-P. Duvel, 2013: Understanding Madden-Julian-Induced sea surface temperature variations in the North Western Australian Basin, Clim. Dyn. doi: 10.1007/s00382-012-1541-7

Vialard. J., A. Jayakumar, C. Gnanaseelan, M. Lengaigne, D. Sengupta, 2012: Processes of intraseasonal sea surface temperature variability in the Northern Indian Ocean during boreal summer. Clim. Dyn., 38, 1901-1916.

Wang, L., C. J. Koblinsky, and S. Howden, 2001: Annual Rossby Wave in the Southern Indian Ocean: Why Does It Appear" to Break Down in the Middle Ocean?, J. Phys. Oceanogr., 31, 54- 74.

Wu, R., B. P. Kirtman, and V. Krishnamurthy (2008), An asymmetric mode of tropical Indian Ocean rainfall variability in boreal spring, J. Geophys. Res., 113, D05104, doi:10.1029/2007JD009316.

Webster, P. J., Moore, A. M, Loschnigg, J. P, and Leben, R. R, 1999: Coupled ocean atmosphere dynamics in the Indian Ocean during 1997-98, Nature, 401, 356-360.

Xie, P., P. A. Arkin, 1997: Global precipitation: a 17-year monthly analysis based on gauge 
observations, satellite estimates, and numerical model outputs. Bull Am Meteor Soc, 78:2539-2558

Xie, S-P., Annamalai. H, Schott. F.A, McCreary. J. P, 2002: Structure and mechanisms of south Indian climate variability. J. Clim, 9, 840-858

Xie, S-P., Hu. K, Hafner. J, Du. Y, Huang. G, Tokinaga. H, 2009: Indian Ocean capacitor effect on Indo-western Pacific climate during the summer following El Nino. $J$ Clim., 22, 730-747

Yamagata, T., Behera. S. K, Luo .J-J, Masson. S, Jury. M, Rao. S. A, 2004: Coupled ocean atmosphere variability in the tropical Indian Ocean, in earth climate: the oceanatmosphere interaction. In: Wang C, Xie S-P, Carton JA (eds) Geophysical monograph series, 147. AGU, Washington, DC, pp 189-212

Yokoi, T., T. Tozuka, and T. Yamagata, 2008: Seasonal variation of the Seychelles Dome. J. Clim., 21, 3740-3754.

Yokoi, T. and T. Tozuka, 2009: Seasonal variation of the Seychelles Dome simulated in the CMIP3 models. J. Phys. Oceanogr., 39, 449-457

Yokoi, T., T. Tozuka, and T. Yamagata, 2012: Seasonal and interannual variations of the SST above the Seychelles Dome, J. Clim., 25, 800-814

Yu, W., B. Xiang, L. Liu, and N. Liu, 2005: Understanding the origins of interannual thermocline variations in the tropical Indian Ocean, Geophys. Res. Lett., 32, L24706, doi:10.1029/2005GL024327.

Zhang, C., 2005: Madden-Julian Oscillation, Rev. Geophys., 43, RG2003, doi:10.1029/2004RG000158.

Zhang, Y. C., W. B. Rossow, A. A. Lacis, V. Oinas, and M. I. Mishchenko, 2004: Calculation of radiative fluxes from the surface to top of atmosphere based on ISCCP and other global data sets: Refinments of the radiative transfer model and the input data. J. Geophys. Res., 109, D19105, doi:10.1029/2003JD004457.

\section{Figures}

Figure 1. Climatological mean Sea Surface Temperature $\left({ }^{\circ} \mathrm{C}\right.$; in colors, from TropFlux), wind stress ( $\mathrm{Nm}^{-2}$; arrows, from TropFlux) and depth of the $20^{\circ} \mathrm{C}$ isotherm (D20 in m, from World Ocean Atlas - WOA09) for the DJF season. The black box $\left(50^{\circ} \mathrm{E}-80^{\circ} \mathrm{E}, 5^{\circ} \mathrm{S}-12^{\circ} \mathrm{S}\right)$ indicates the thermocline ridge of the Indian Ocean (TRIO) region. The CIRENE cruise $1^{\text {st }}$ leg track is indicated in green lines with numbers 1-3 representing three sections. Blue dashed lines indicate the $2^{\text {nd }}$ CIRENE leg. The small black square $\left(8^{\circ} \mathrm{S}, 67.5^{\circ} \mathrm{E}\right)$ indicates the location of the Cirene cruise long CTD station that is used in figure 7.

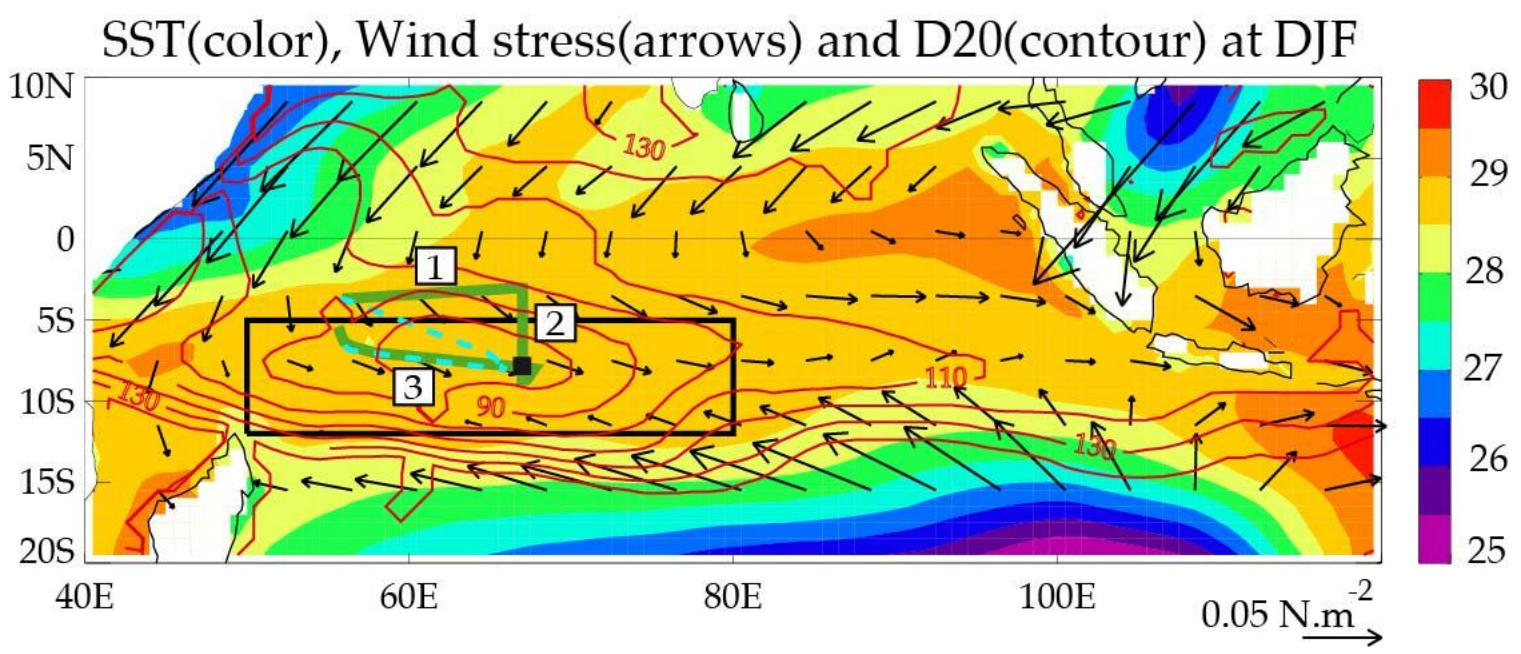


Figure 2: (a) Demeaned seasonal variations of D20 and sea level; (b) standard deviation of interannual D20 anomalies; and (c) standard deviation of interannual SST anomalies averaged over the TRIO $\left(50^{\circ} \mathrm{E}-80^{\circ} \mathrm{E}, 5^{\circ} \mathrm{S}-12^{\circ} \mathrm{S}\right)$ region shown in figure 1 . Observations (TropFlux for SST and SODA 2.2.4 for D20) are shown as full lines and the model as dashed lines. The standard deviations and seasonal cycles are computed over the 19942007 period.

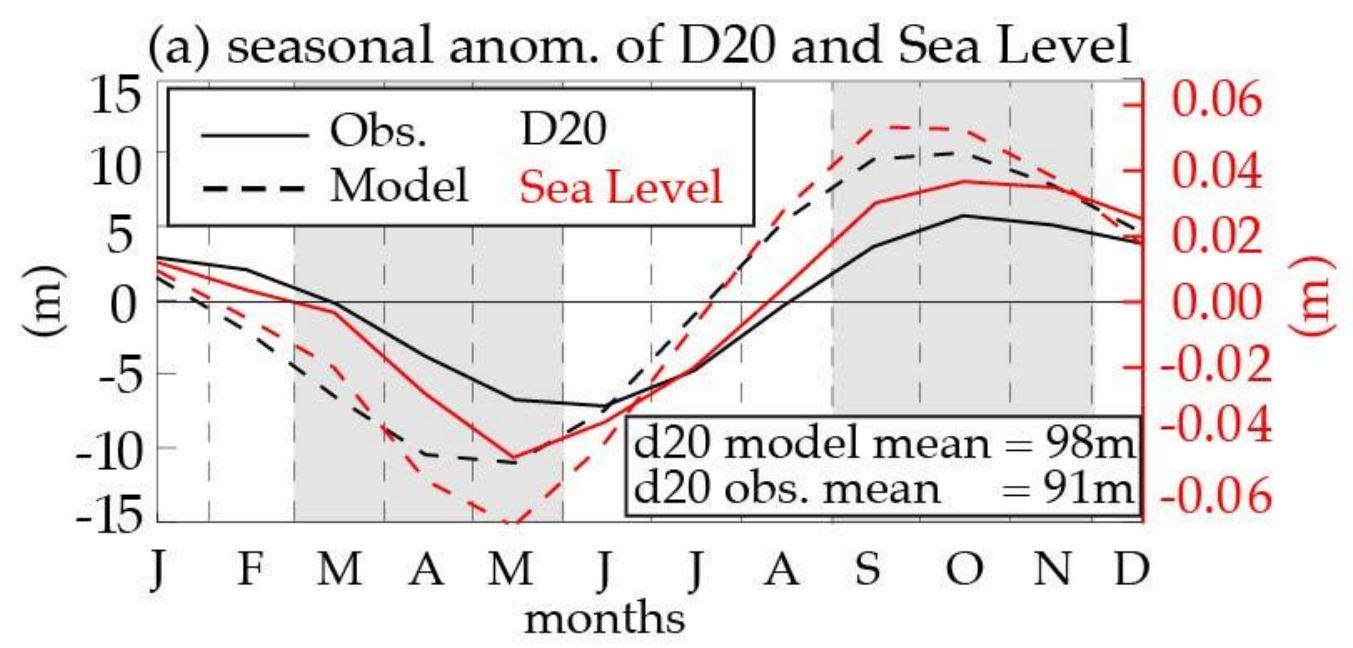

(b) standard deviation of D20A

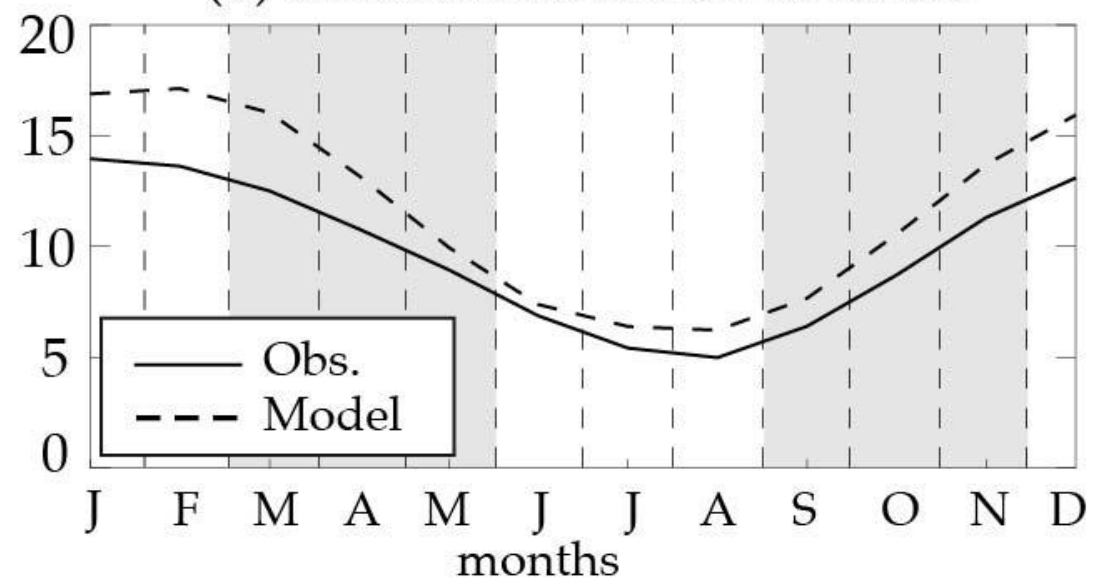

(c) standard deviation of SSTA




Figure 3: Area-averaged seasonal cycles of (a) Sea Surface Temperature (SST), (b) Mixed Layer Depth (MLD), (c) surface currents, (d) Net Heat Flux and its components and (e) mixed layer temperature tendency terms in the TRIO region. Observations are shown as solid lines and model as dashed lines. The following observational products are used: (a) TropFlux SST, (b) de Boyer Montégut (2004) MLD, (c) OSCAR currents and (d) TropFlux heat fluxes. The seasonal cycle is calculated over the 1994-2007 period for both model and observations.

(a) SST seasonal cycle

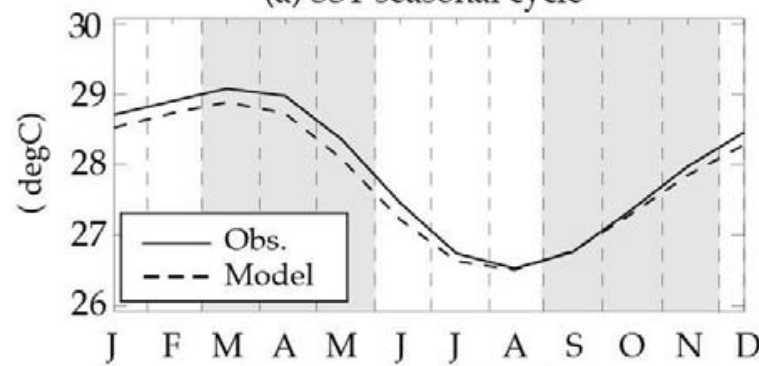

(b) MLD seasonal cycle

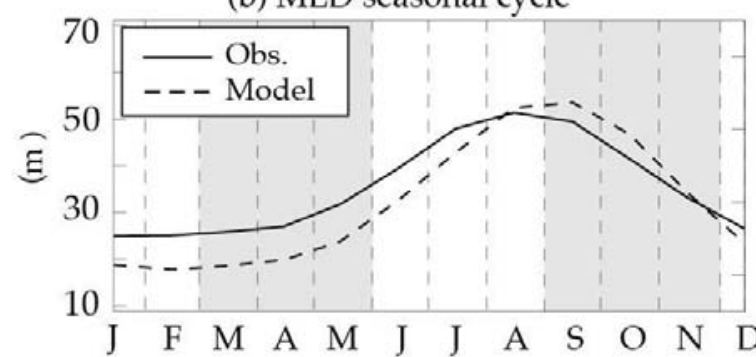

(c) Currents seasonal cycle

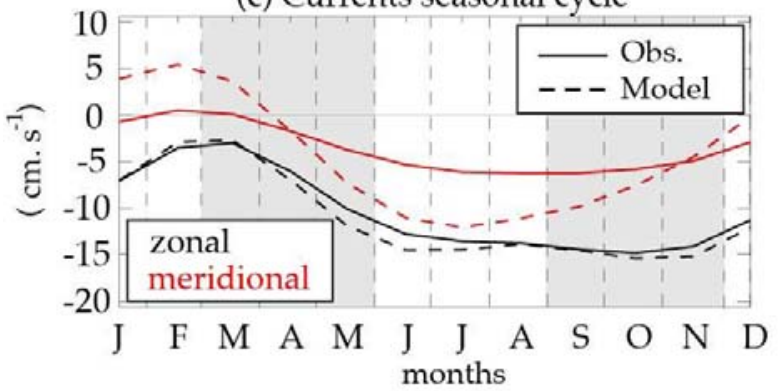

(d) Fluxes seasonal cycle

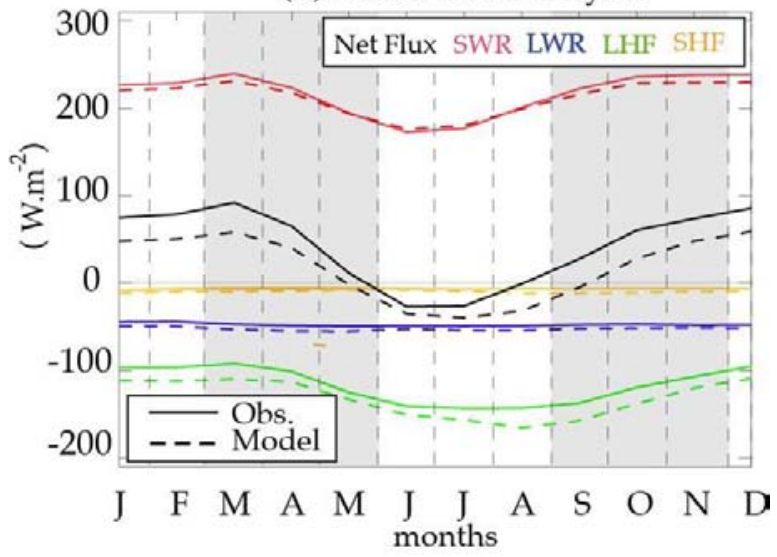

(e) Temperature tendency seasonal cycle

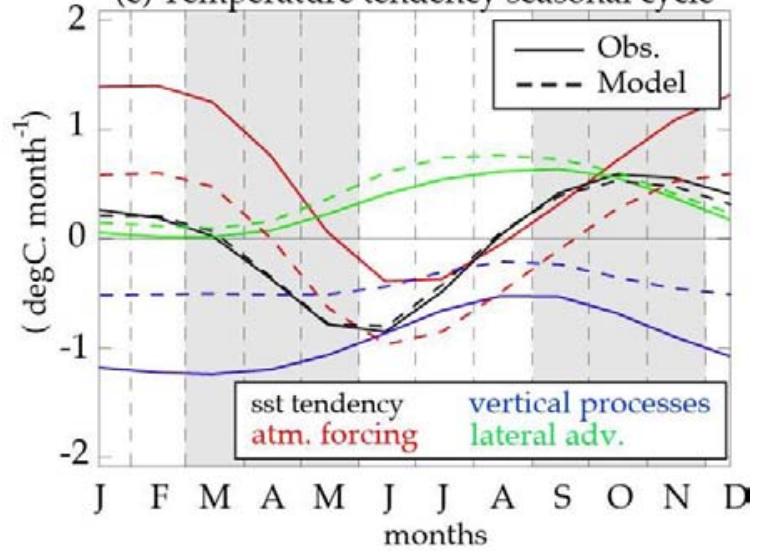


Figure 4. Comparison of average modeled (dashed line) and observed (continuous line) interannual anomalies of (a) SST, (b) mixed layer depth, (c) net heat fluxes, (d) zonal and meridional currents and (e) sea level over the TRIO region (see figure 1). All anomalies are calculated based on the 1994-2007 period except for MLD (which uses the full available 2003-2007 record for anomaly estimation). In panel (d) zonal current anomalies are shown as thin lines and meridional current anomalies are shown as thick lines. The correlation and standard deviation ratio between model and observations are indicated in each panel. Statistics are estimated based on the 1994-2007 period (except for MLD: 2003-2007). The Cirene cruise period (Jan-Feb 2007) is indicated as a grey strip in all panels. The red and blue shading indicates SON of positive and negative IOD events respectively (Meyers et al. 2007). Observations use the TropFlux SST and net heat fluxes, de Boyer Montégut et al (2004) MLD, OSCAR currents and AVISO sea level data.

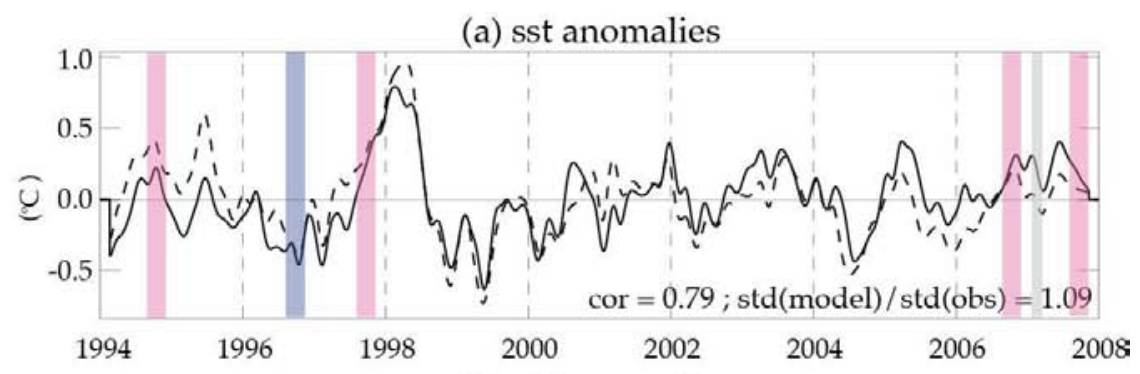

(b) mld anomalies

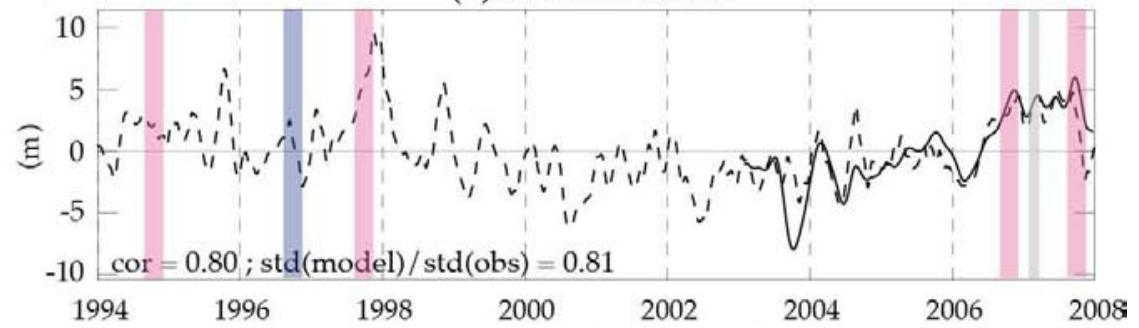

(c) net heat flux anomalies

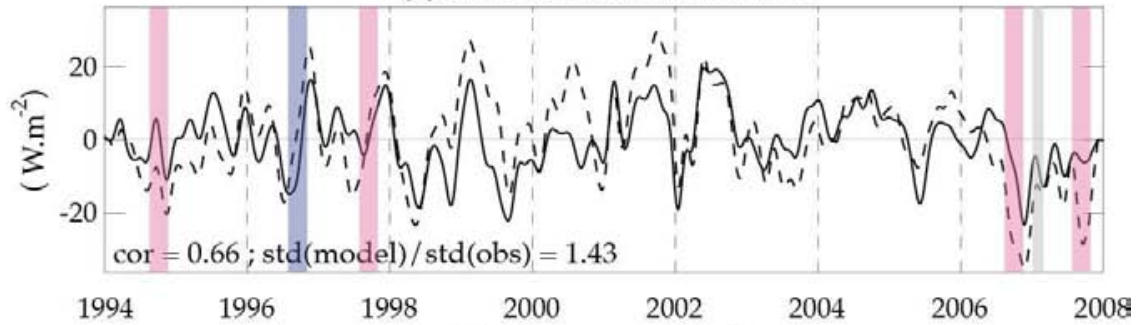

(d) current anomalies

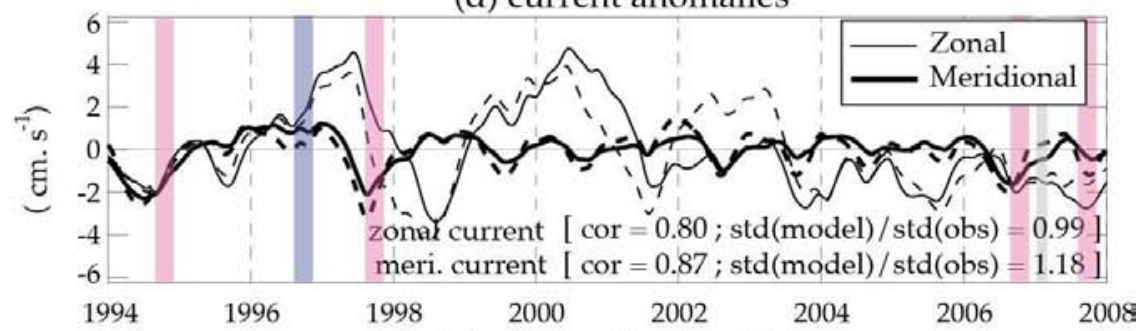

(e) sea level anomalies

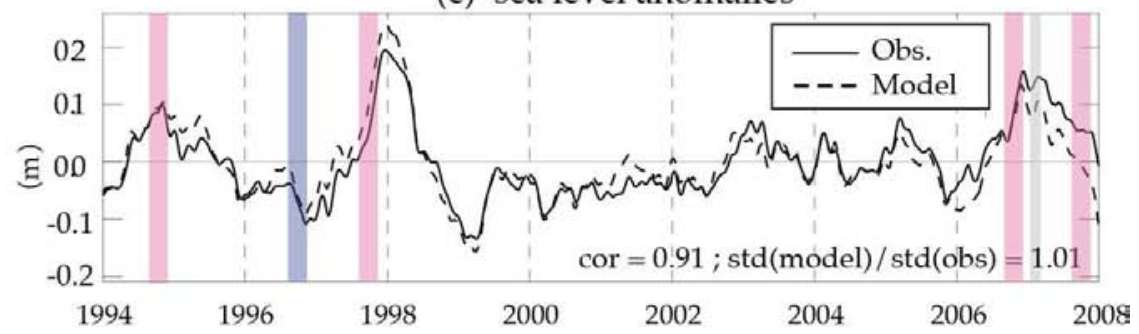


Figure 5: Sea Level, which is a proxy for the upper ocean heat content (color shading) and interannual anomalies of surface currents (vectors) from (a) observations and (b) the model during the Cirene cruise period (14-26 January 2007). The black box $\left(50^{\circ} \mathrm{E}-80^{\circ} \mathrm{E}, 5^{\circ} \mathrm{S}-\right.$ $12^{\circ} \mathrm{S}$ ) outlines the TRIO region. The CIRENE cruise first leg is indicated with green lines, and the numbers 1-3 represent three sections. Observational current anomalies are from the OSCAR product and sea level anomalies are from AVISO sea level data. The small black square indicates the location $\left(8^{\circ} \mathrm{S}, 67.5^{\circ} \mathrm{E}\right)$ of the Cirene cruise long CTD station that is used in figure 7.

(a) sla (color) and current anom. (vector) - obs

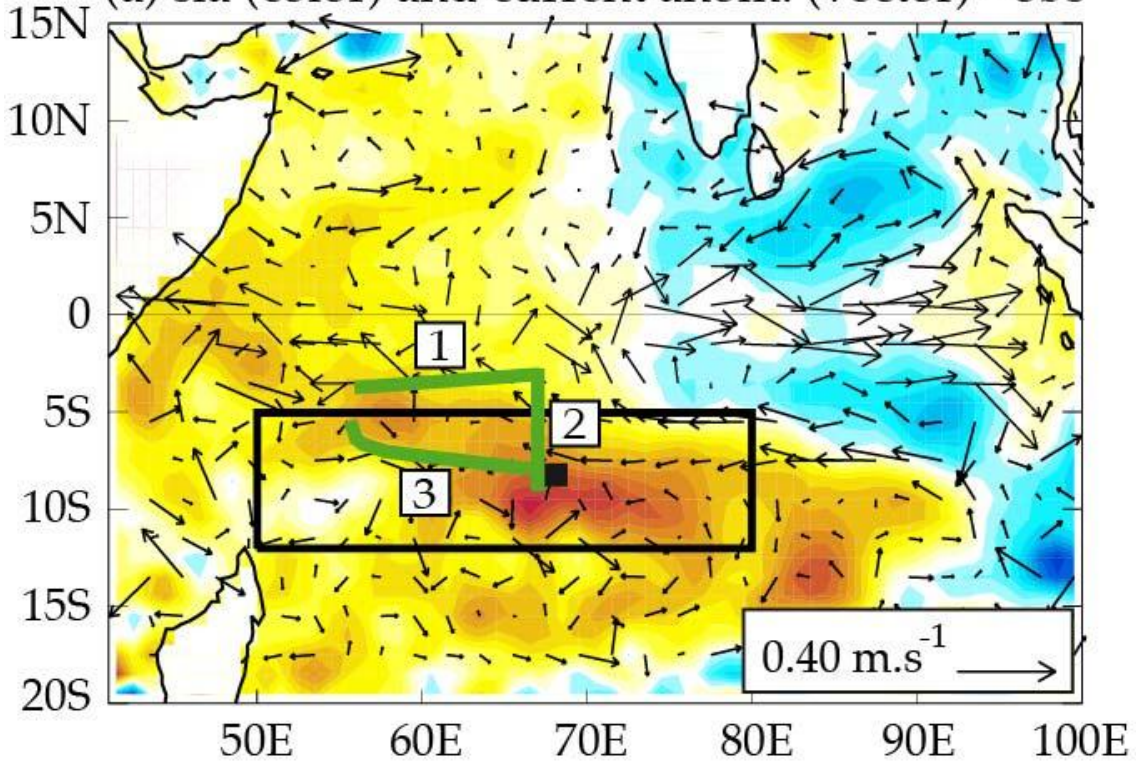

(b) sla (color) and current anom. (vector) - model

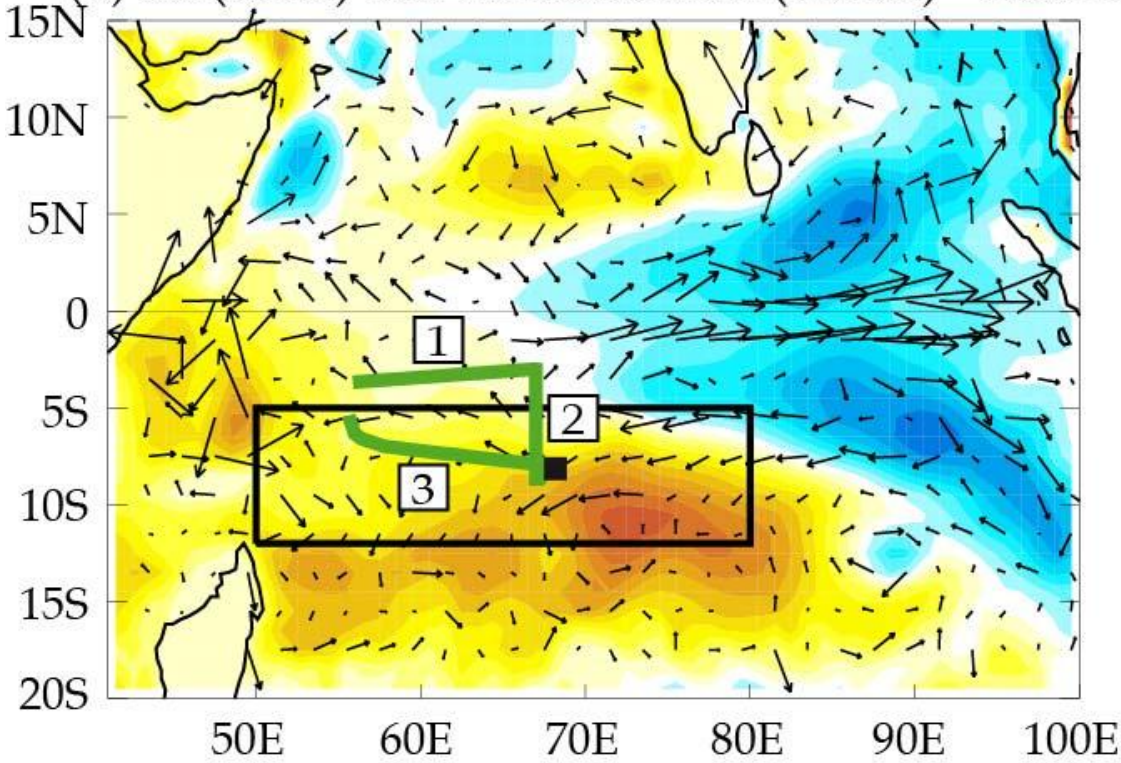

\begin{tabular}{llllllll}
\hline & & & & & & & $(\mathrm{m})$ \\
-0.30 & -0.20 & -0.10 & -0.00 & 0.10 & 0.20 & 0.30
\end{tabular}


Figure 6. Vertical temperature anomalies from XBT observations for the Cirene cruise (left panel) and from the model (right panel) in early 2007. The sections (a) and (b) are along the $8^{\circ} \mathrm{S}$ oblique zonal section labeled (3) in figure 5; (c) and (d) are along the $67^{\circ} \mathrm{E}$ meridional section labeled (2) on figure 5 . Anomalies are computed with respect to the 1994-2007 average for the model and to the WOA09 climatology for observations.
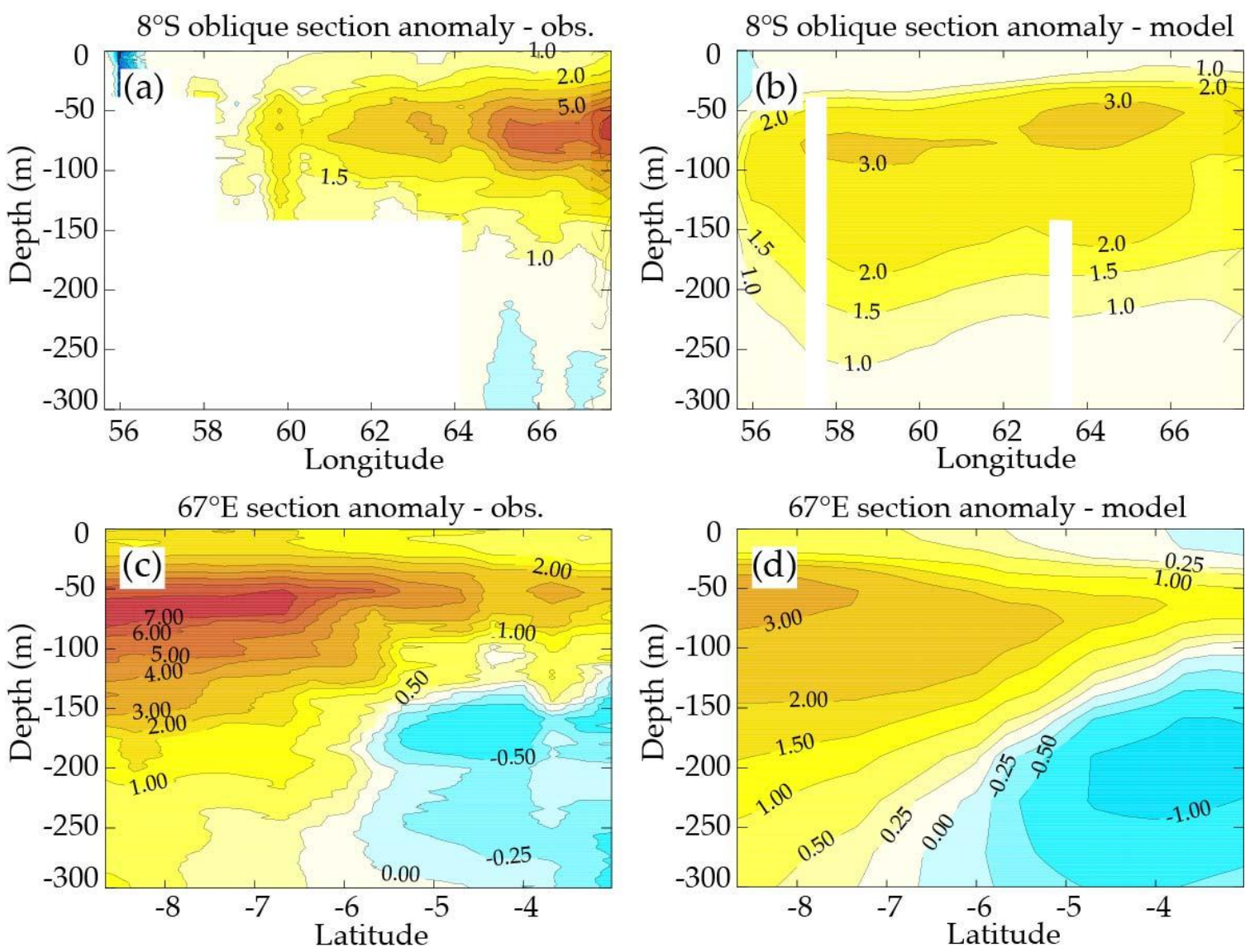
Figure 7. Anomalous subsurface conditions observed at $8^{\circ} \mathrm{S}, 67^{\circ} \mathrm{E}$ in early 2007 (14-26 January 2007): (a) temperature, and (b) currents. The model anomalies are computed with respect to the January climatology over the 1994-2007 period. Observed temperature anomalies are calculated as deviations of 14-26 January 2007 Cirene cruise data from the WOA09 climatology. Observed current anomalies are calculated with respect to currents deduced from the WOA09 climatology using the thermal wind relation (with a reference level at $1000 \mathrm{~m}$ ). Observed anomalies are shown as continuous lines while model anomalies are shown as dashed lines. In panel (b) zonal current anomalies are shown as thin lines while meridional current anomalies are shown as thick lines.

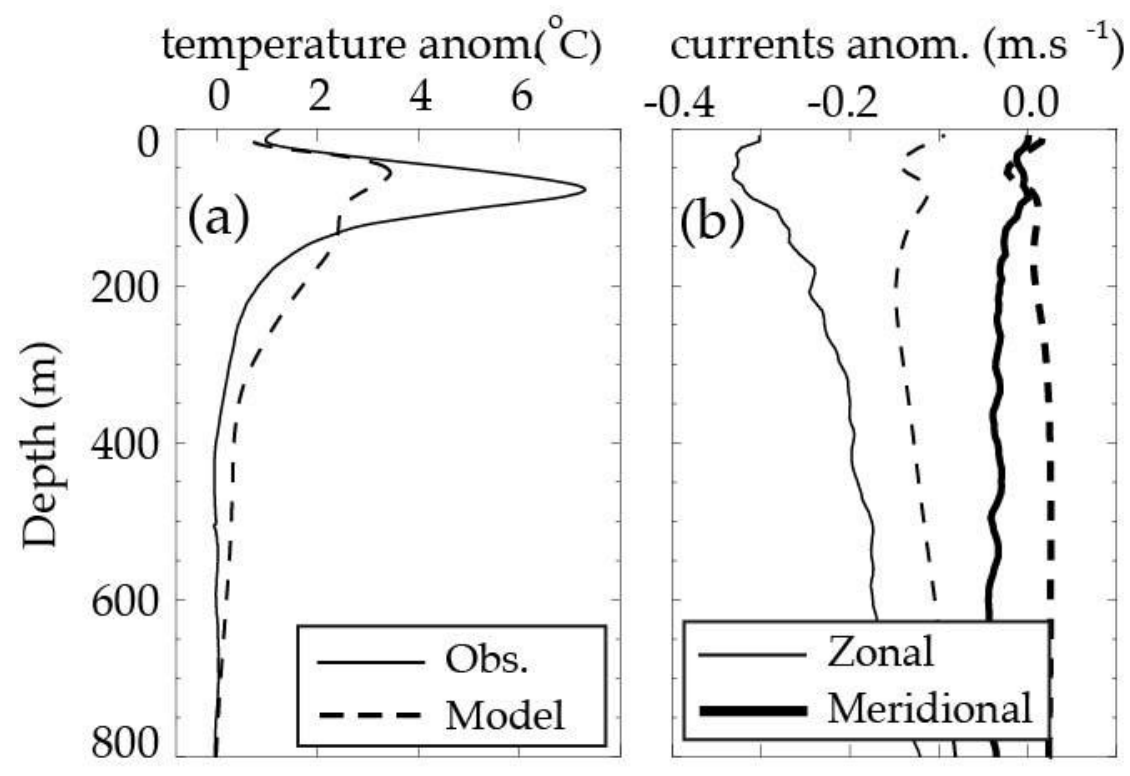

Figure 8. Seasonal cycle of interannual anomalies in the Temperature Variance Budget (TVB, see section 2.4 for details) over the TRIO region from (a) observations and (b) model. A black line (total tendency) below (above) zero indicates a period of the year when SST interannual anomalies tend to decrease (increase). The shading shows one standard deviation from the mean value. This analysis is done over 1994-2007.
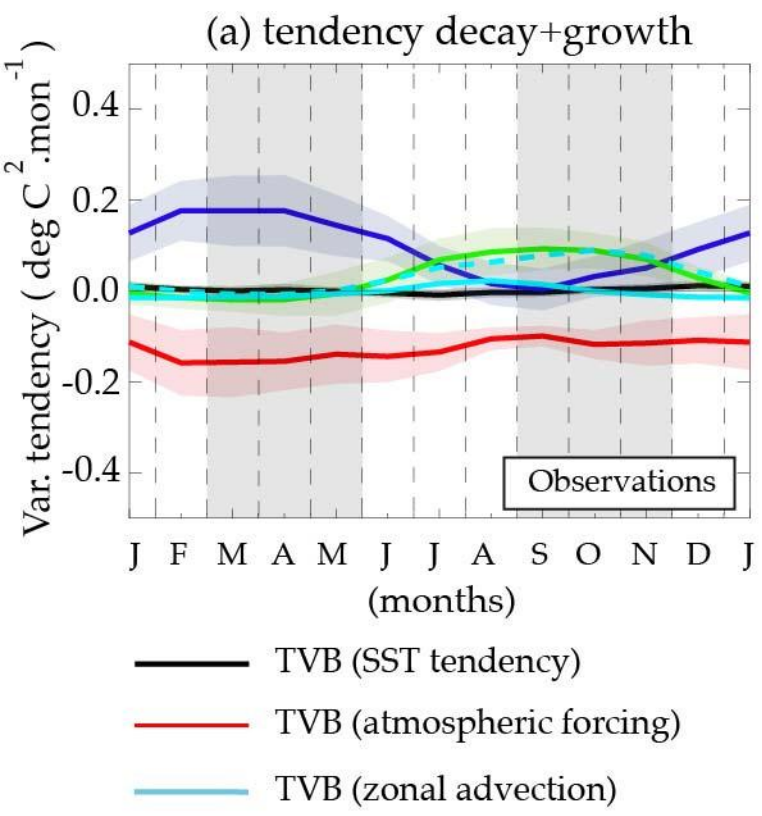

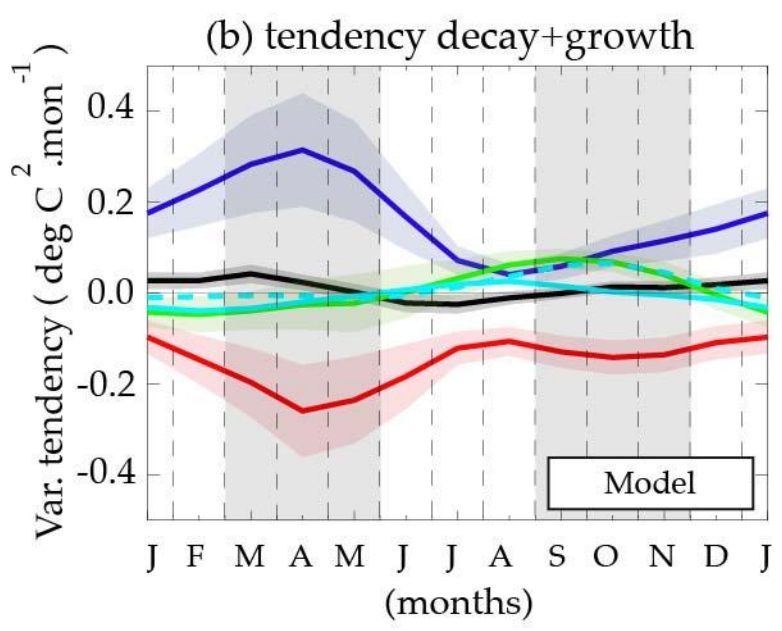

TVB (vertical processes) TVB (lateral advection) TVB (meridional advection) 
Figure 9: Decomposition of various heat flux component contributions to the mean seasonal cycle of SSTA variance induced by the atmospheric forcing term. Various flux components are shown in different colors. The overlying red line indicates the net TVB atmospheric forcing term denoted by the red curves in figure 8 .

(a) TVB of heat flux components - obs

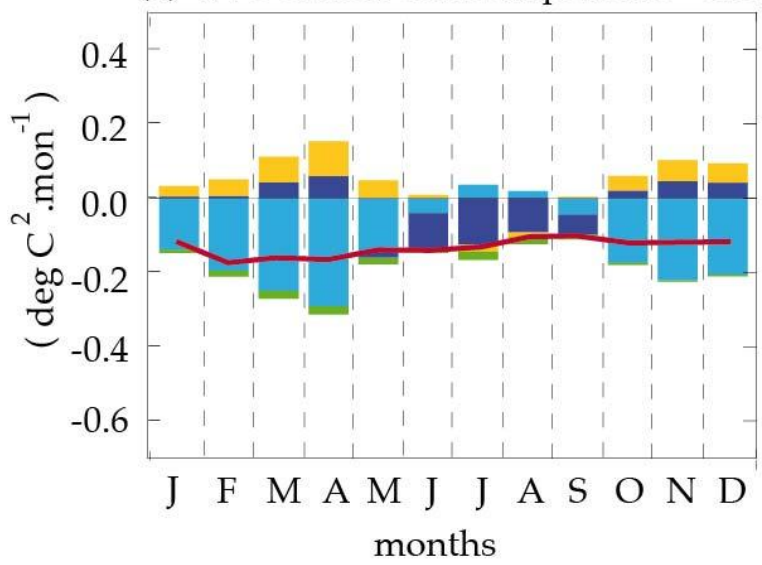

(b) TVB of heat flux components - model

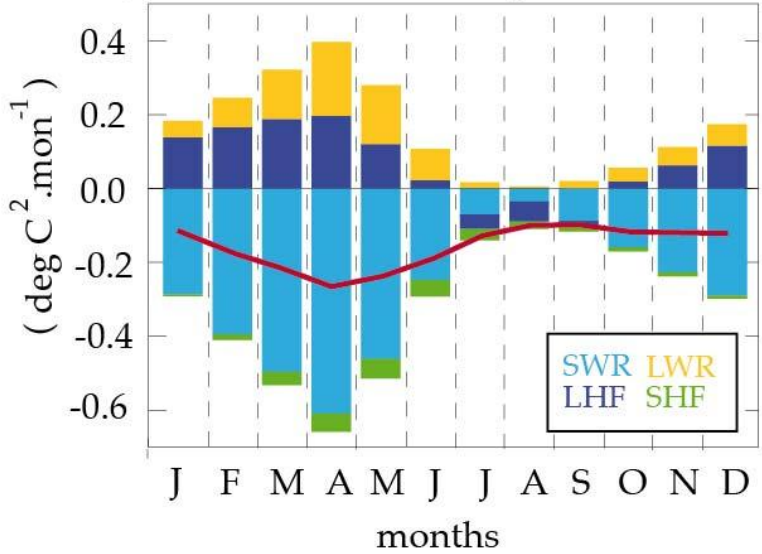

Figure 10: Upper panel show the seasonal cycle of meridional advection and its contribution from $-V \partial_{y} \bar{T}$ and $-\bar{V} \partial_{y} T^{\prime}$ components from (a) observations and (b) model (the $-V \partial_{y} T^{\prime}$ term has not been plotted for clarity, but this term is small). The dashed cyan line indicates the meridional advection contribution as seen in figure 8. Panel (c) shows the seasonal cycle of meridional currents (black lines) and standard deviation of meridional current anomalies (red lines). Panel (d) shows the seasonal cycle of meridional SST gradient (black lines) and standard deviation of meridional anomalous SST (red lines). In the bottom panel observations are shown as full lines and model simulations as dashed lines.

(a) TVB meri. adv. components - Obs

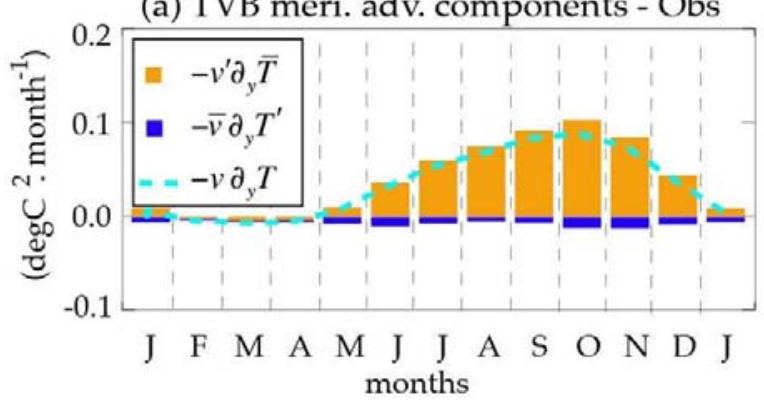

(c) seasonal cycle of $\bar{V}$, and std. of $V^{\prime}$

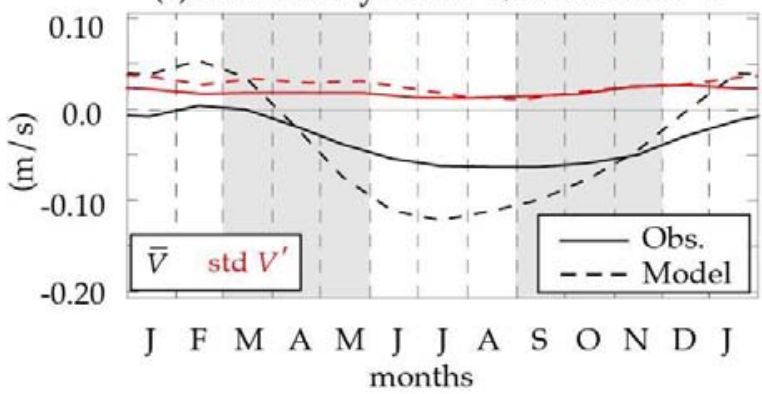

(b) TVB meri. adv. components - Model

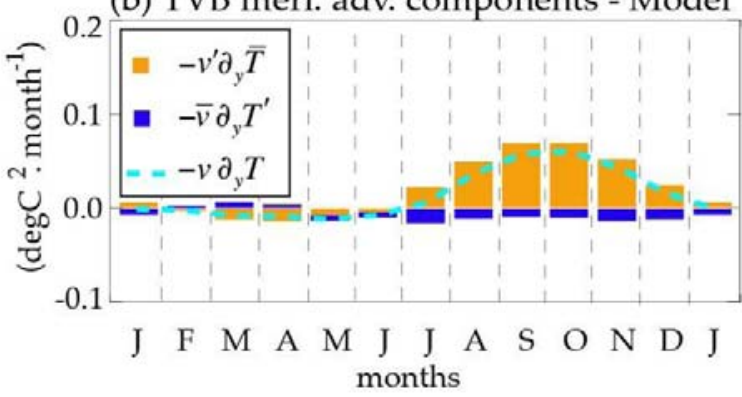

(d) seasonal cycle of $\partial_{y} \bar{T}$, and std. of $\partial_{y} T$

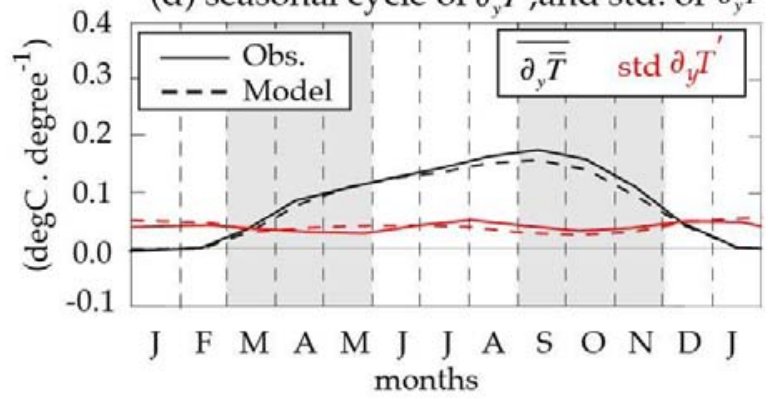


Figure 11: Typical evolution of the interannual anomalies associated with the Indian Ocean Dipole (IOD, left column) and EI Niño (right column) averaged over the TRIO region. (a) and (c): SSTA $\left({ }^{\circ} \mathrm{C}\right.$, red) and surface net heat flux $\left(\mathrm{Wm}^{-2}\right.$, black). (b) and (e): sea level (m, black) and currents ( $\mathrm{cm} \mathrm{s}^{-1}$, red). (c) and (f): surface mixed layer temperature heat budget $\left({ }^{\circ} \mathrm{C}\right.$ month $^{-1}$, see inset for details). This analysis is made based on the $2^{\circ}$ resolution model results, over the 1984-2007 period. The IOD and EI Niño signals are obtained using a partial regression method to the average September-November Dipole Mode Index and to the November-January Niño3.4 index (see text for details).
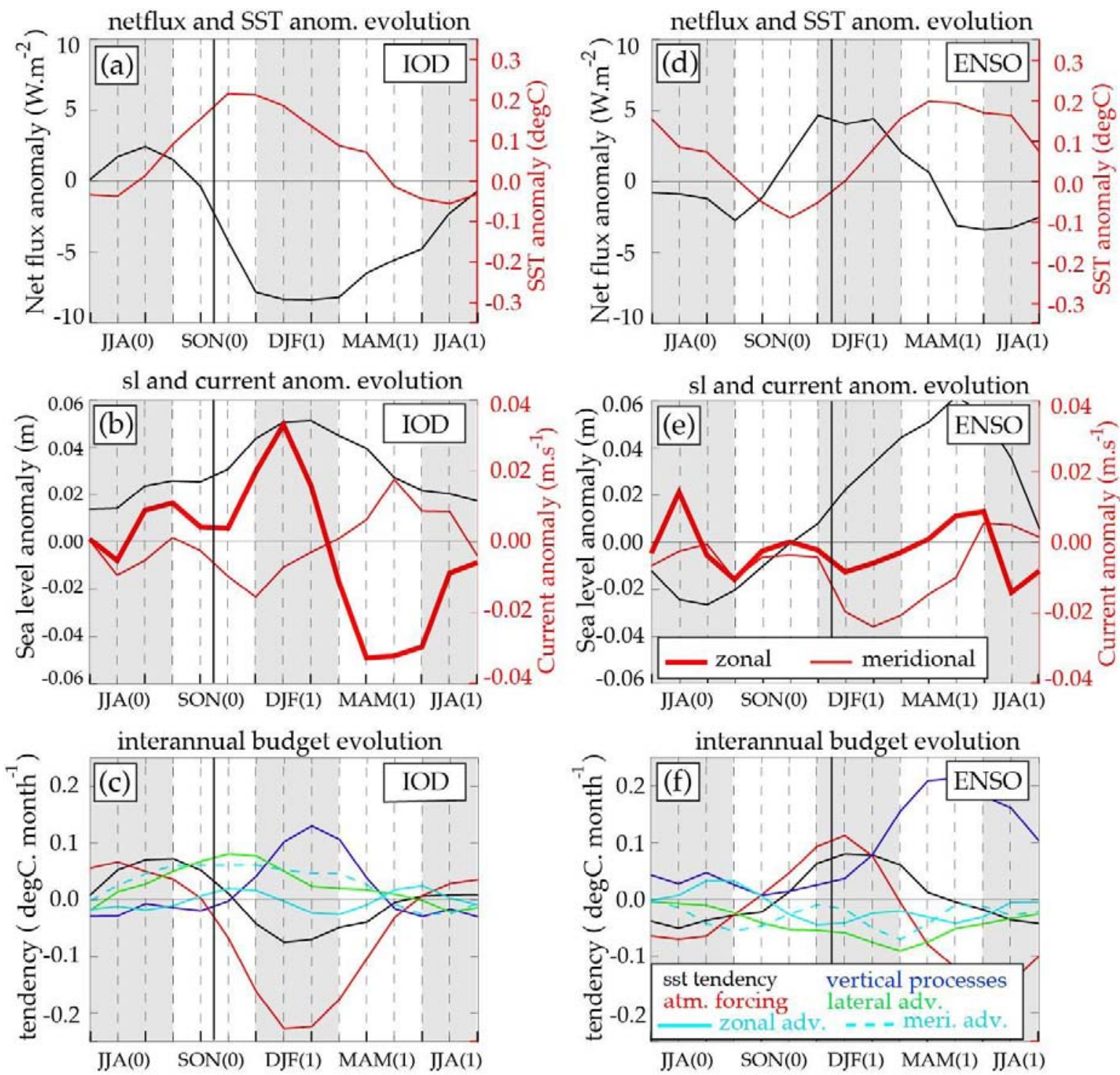
Figure 12. Evolution of tropical Indian Ocean sea level anomalies ( $m$, colors on the left panel), current anomalies ( $\mathrm{ms}^{-1}$, vectors on the left panel), SST anomalies $\left({ }^{\circ} \mathrm{C}\right.$, colors on the right panel) and net heat flux anomalies (contours on the right panel) associated with a typical IOD event, obtained from the $2^{\circ}$ resolution model results over 1984-2007. The IOD and ENSO signals are separated using a partial regression method to the average September-November Dipole Mode Index and to the November-Januaray Niño3.4 index (see text for details).

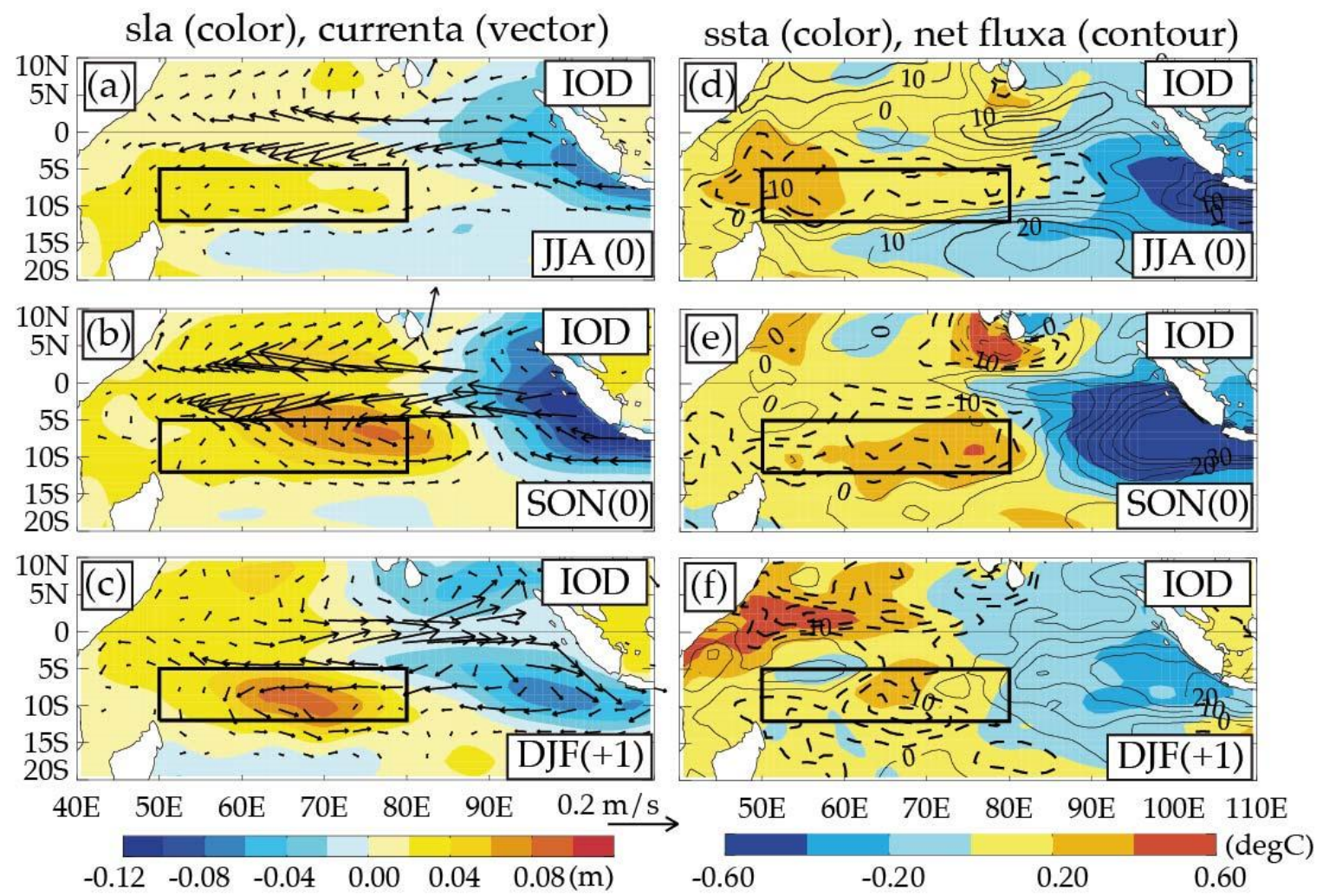


Figure 13. Evolution of tropical Indian Ocean sea level anomalies ( $m$, colors on the left panel), current anomalies $\left(\mathrm{ms}^{-1}\right.$, vectors on the left panel), SST anomalies $\left({ }^{\circ} \mathrm{C}\right.$, colors on the right panel) and net heat flux anomalies (contours on the right panel) associated with a typical ENSO event, obtained from the $2^{\circ}$ resolution model results over 1984-2007. The IOD and ENSO signals are separated using a partial regression method to the average September-November Dipole Mode Index and to the November-January Niño3.4 index (see text for details).


Figure 14: (a) Climatological SST pattern in the tropical Indian Ocean and anomalous currents associated with IOD for SON(0). (b) Climatological SST pattern and anomalous SST associated with ENSO for DJF(1). This analysis is made based on the $2^{\circ}$ resolution model results, over the 1984-2007 period. The IOD and ENSO signals are obtained using a partial regression method to the average September-November Dipole Mode Index and to the November-Januaray Niño3.4 index (see text for details).

(a) SST clim, current anom. (IOD)

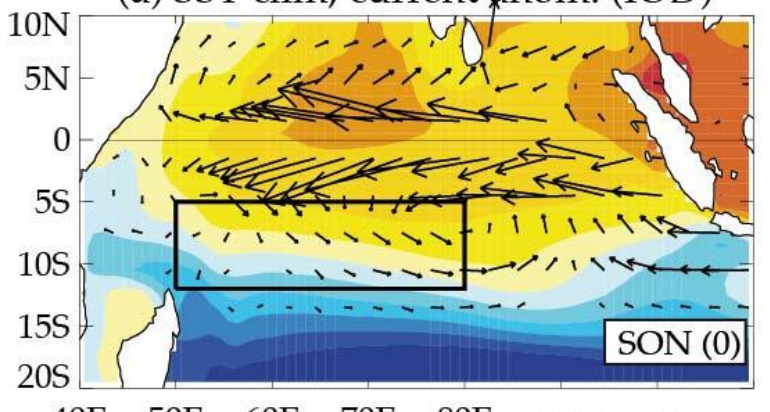

(b) SST anom., current clim. (ENSO)

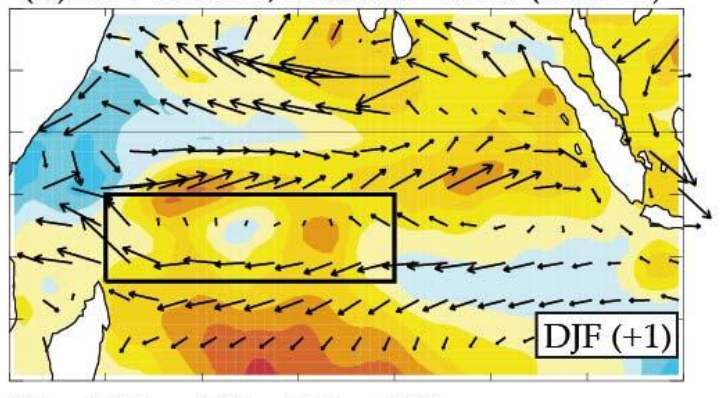

$40 \mathrm{E} \quad 50 \mathrm{E} \quad 60 \mathrm{E} \quad 70 \mathrm{E} \quad 80 \mathrm{E} \quad 0.50 \mathrm{~m}^{-1} \mathrm{~s}^{-1} \longrightarrow$

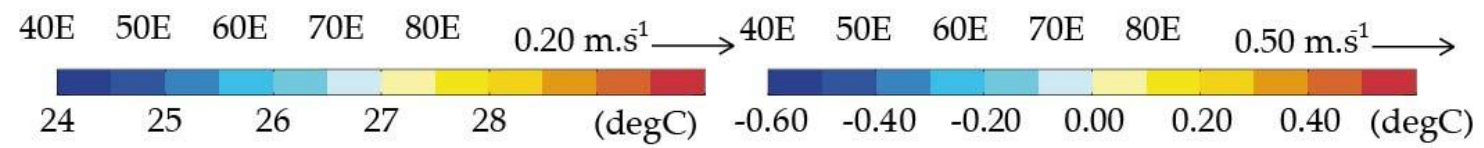


Figure 15: Processes of warming and cooling associated with (a) IOD and (b) ENSO in the TRIO region. SST anomaly related with IOD and ENSO are shown in the two panels where red shading shows positive and blue shading show negative SSTAs. The red and blue strips show periods of SST growth and SST decay respectively. The TVB terms associated with IOD and ENSO related SSTAs are shown as bar diagrams in the insets.

(a) IOD processes

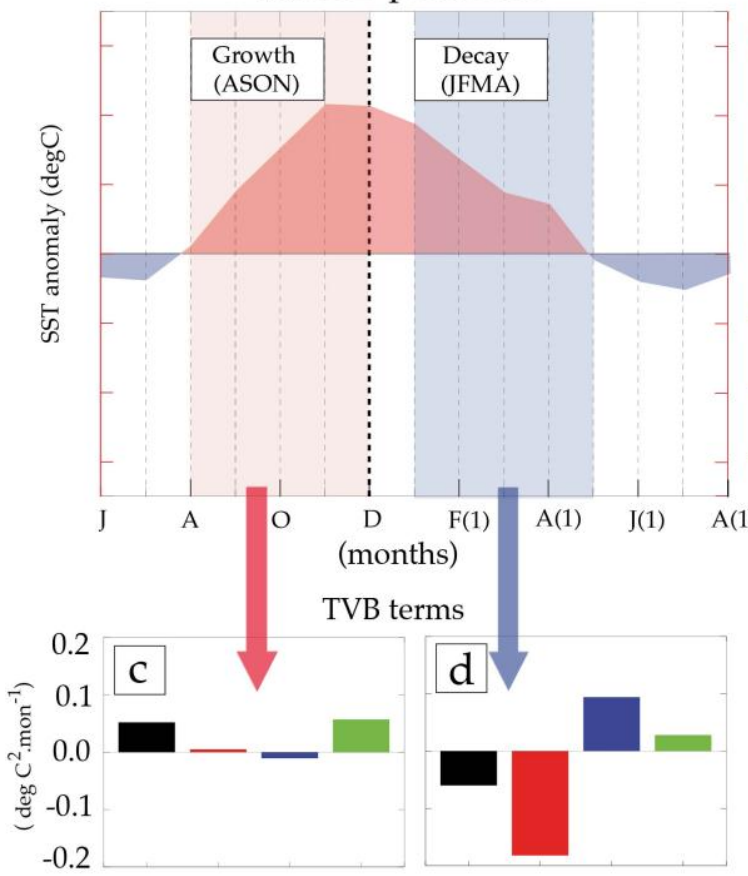

(b) ENSO processes

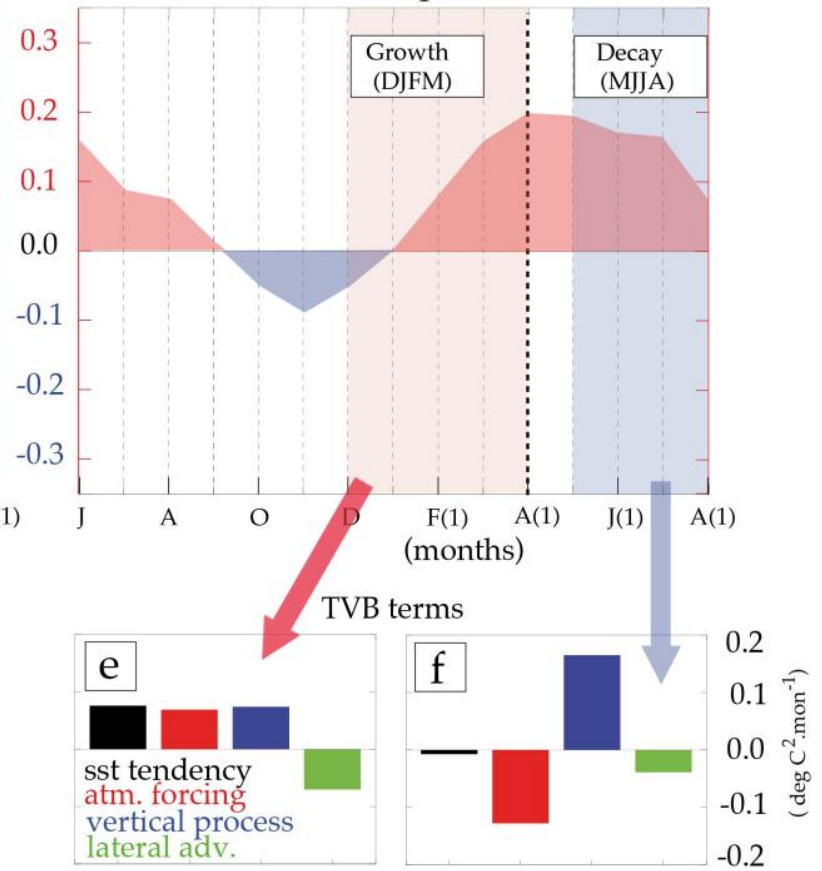

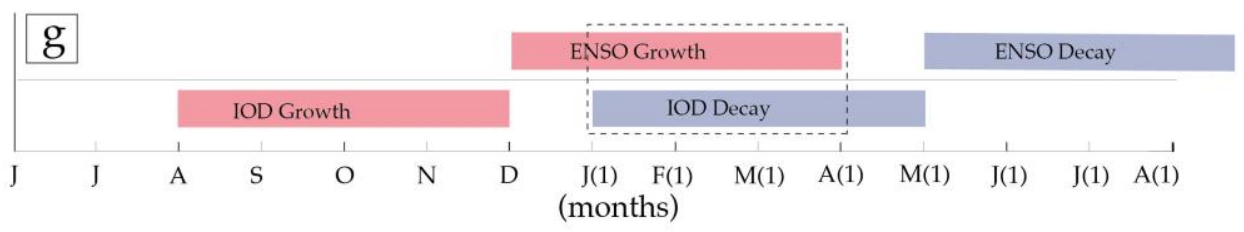

